\title{
Coronary Embolization and Myocardial Microinfarction: MR Imaging and Histopathologic Characterization
}

\author{
Maythem Saeed*, Steven W. Hetts, Anqi Liang, Mark W. Wilson \\ Department of Radiology and Biomedical Imaging, School of Medicine University of California San Francisco, \\ San Francisco, CA, USA \\ Email: *Maythem.Saeed@ucsf.edu
}

Received 17 February 2016; accepted 27 June 2016; published 30 June 2016

Copyright (C) 2016 by authors and Scientific Research Publishing Inc.

This work is licensed under the Creative Commons Attribution International License (CC BY).

http://creativecommons.org/licenses/by/4.0/

(c) (i) Open Access

\begin{abstract}
Magnetic resonance imaging (MRI) has been proven to reliably assess regional perfusion and left ventricular (LV) function of microembolized myocardium. The visibility of microinfarct on delayed enhancement MRI (DE-MRI) is limited and dependent on technical and biological issues. Furthermore, MRI underestimates total microinfarct size compared with microscopy. MRI studies revealed that the presence of microemboli in pre-existing acute infarct delays infarct healing and magnifies LV remodeling. Discrimination of acute from chronic microinfarct is based on presence of inflammatory cells, edema and scar tissue, respectively. These noninvasive findings highlight the importance of prognostic utility of MRI and warrant larger clinical studies or registries to evaluate the significance of presence of focal microinfarct. Serial microscopic studies revealed that intravascular microemboli migrate into the extravascular space and this migration process is a function of time. This phenomenon may limit the use of microemboli therapy in occluding hemorrhagic blood vessels or treating tumors. Despite current standard of care, existing methods and therapies do not prevent coronary embolization nor reverse their deleterious effects.
\end{abstract}

\section{Keywords}

Percutaneous Coronary Revascularization, Coronary Microembolization, Myocardial Microinfarct, Magnetic Resonance Imaging, Microscopy

\section{Introduction}

Every minute more than one person suffers from acute myocardial infarction (AMI) in the United States [1].

${ }^{*}$ Corresponding author.

How to cite this paper: Saeed, M., Hetts, S.W., Liang, A. and Wilson, M.W. (2016) Coronary Embolization and Myocardial Microinfarction: MR Imaging and Histopathologic Characterization. International Journal of Clinical Medicine, 7, $399-418$. 
Thromboembolic occlusions occur as a result of spontaneous clot formation and dislodgment of atherosclerotic plaques [2]. For patients presenting with an acute myocardial infarction, numerous revascularization strategies have been developed in an attempt to reduce infarct size, limit onset of heart failure and improve both left ventricular (LV) function and clinical outcome. Previous studies showed that over one million percutaneous coronary intervention (PCI) procedures are performed annually in the United States [3]. Paradoxically, revascularization of infarct-related coronary artery could produce further damage to previously undamaged myocardium by dislodged microemboli and a phenomenon called reperfusion injury. Clinical studies confirmed that PCI to break down large clots generates microemboli that occlude downstream microvessels [3] [4]. Cuculi et al. showed that $5 \%-30 \%$ of the patients suffered from coronary embolization after PCI [5] and the effects on myocardium varied from non-symptomatic to sudden death [6]-[8]. This review addresses the use of MRI and microscopy in characterizing coronary microembolization and myocardial microinfarct.

\section{Coronary Emboli}

Autopsy studies showed that coronary embolization occurred 3 to 4 times more often in the left coronary artery than in the right, and in the left anterior descending (LAD) than in the left circumflex coronary artery [9]. The middle range of the size of coronary micoemboli retrieved after coronary intervention was 47 - $2503 \mu \mathrm{m}$. Coronary embolization describes a process where aggregated dislodged platelets, atherothrombotic debris and released vasoactive substances induce microvascular obstruction, inflammation and patchy microinfarction. Coronary embolization also occurs in spontaneous atherosclerosis plaque rupture, valvular disease, endocarditis, arrhythmias, heart-lung bypass surgery, congenital heart disease, hypertension, diabetes, systemic lupus erythematosus and sickle cell disease.

In a recent study, Grutzendler et al. [10] proved that microemboli could be cleared from microvessels by angiophagy, in which emboli are were engulfed by the endothelium and they translocated through the micro-vascular wall. The engulfment of emboli by the endothelial membrane projections leads to reestablishment of blood flow, vessel sparing and salvaged ischemic tissues. The molecular control of the extravasation mechanism involves mechanotransduction, vascular plasticity, cytoskeletal dynamics and remodeling of endothelial junctions [11].

\section{Cardiac Injury Biomarkers}

Cardiac injury occurs when there is disruption of myocyte membrane integrity that results in the loss into the interstitial and blood of intracellular constituents, such as creatine kinase MB (CK-MB), troponin I, myoglobin, heart-type fatty acid binding protein, and lactate dehydrogenase.CK-MB and troponin elevations in the blood are indicative of myocardial injury in patients. Thus, the diagnosis of AMI has become increasingly dependent on serum CK-MB and troponin I. However, the elevation of these two biomarkers after microinfarction can be undetected due to their dilution in the large sinus blood flow. After PCI cardiac injury biomarkers have been used to document early myocardial injury caused by microemboli [12] [13]. A large meta-analysis of 23,230 patients with stable or unstable angina undergoing PCI with follow-up for 6 - 34 months compared with the data from healthy volunteers showed a close relationship between CK-MB concentration and mortality rate, even at a minor increase of CK-MB 1 - $3 \times$ conferring a relative risk of death of 1.5 (95\% CI 1.2 to 1.8) [14].

In an experimental study [15], investigators found after $24 \mathrm{hrs}$ PCI that plasma concentrations of CK-MB and troponin I were significantly higher after delivery of $16 \mathrm{~mm}^{3}$ and $32 \mathrm{~mm}^{3}$ microemboli to the LAD coronary artery compared with baseline. However, there was no significant difference at this time point in troponin I after $16 \mathrm{~mm}^{3}(0.52 \pm 0.28 \mathrm{ng} / \mathrm{ml})$ and $32 \mathrm{~mm}^{3}(0.68 \pm 0.4 \mathrm{ng} / \mathrm{ml})$ or CK-MB $(1670 \pm 370 \mathrm{U} / \mathrm{L}$ and $1060 \pm 235 \mathrm{U} / \mathrm{L}$, respectively). After $72 \mathrm{hrs}$, however, the concentration of troponin I was significantly higher $(1.34 \pm 0.43 \mathrm{ng} / \mathrm{ml}$, $P<0.05)$ in animals that received $32 \mathrm{~mm}^{3}$ than the ones receiving $16 \mathrm{~mm}^{3}$ volume $(0.55 \pm 0.28 \mathrm{ng} / \mathrm{ml})$, suggesting that the method of assay of cardiac injury biomarkers at early stage is not sensitive and specific enough to differentiate the effects of varied microemboli volumes.

\section{Non-Invasive Imaging}

Ischemic heart disease can be detected directly on positron emission tomography (PET) and single-photon emission computed tomography (SPECT), MRI, computed tomography (CT), and indirectly on electrocardiography 
(ECG), cardiac injury biomarkers, ventriculography, and echocardiography. PET, SPECT, CT and echocardiography have been the clinical modalities for assessing myocardial perfusion and viability, while intravascular imaging methods, such as optical coherence tomography (OCT) and intravascular ultrasound (IVUS), characterize plaque composition (large necrotic cores, high plaque volume, thin-capped fibroatheroma) [16]-[18]. Echocardiography is the most commonly used clinical method for quantification of global and regional LV function in patients with ischemic heart disease [19]. Investigators also used two-dimensional (2D) speckle-tracking images to measure regional strain and strain rate [20]. This method enables quantifications of LV remodeling [21] and LV reverse remodeling [22].

Porto et al. [23]-[25] were the first to count coronary microemboli in real-time during PCI using high intensity transient signals (HITS) derived from Doppler guidewire. Coronary microembolization has also been linked to myocardial contractile dysfunction, malignant arrhythmias, perfusion deficits and coronary reserve impairment [7] [23] [24] [26]. Few clinical studies showed the potential of MRI in simultaneously estimating LV function and regional perfusion as well as visualization of acute and scarinfarct. However, visualization and quantification of acute and scar microinfarct are still clinically challenging. The variability of patient populations, microemboli volume/size, territory of feeding vessels and cardiac motion play roles in drawing sound conclusions on the deleterious effects of microemboli in addition to the poor spatial resolution of current diagnostic scanners and the lack of suitable quantitative techniques. Investigators found that the controlled preclinical animal models were suitable for resolving the above complexities of myocardial ischemia, reperfusion injury and coronary microembolization. Large animal models were used in many studies to recapitulate the clinical scenario of percutaneous coronary intervention [15] [27]-[30]. In these studies, coronary angiography showed normal epicardial and side branches arteries after embolization. The sizes of chosen microemboli in our studies where in the middle range of the size of microemboli escape the distal protective devices during PCI and the number of microemboli was based on previous animal studies [15] [27]-[30]. It should be noted that currently there is no animal model of spontaneous plaque rupture resulting in coronary microembolization.

\section{Magnetic Resonance Imaging}

Conventional MRI sequences have historically been used in characterization of cardiac anatomy and follow-up of congenital heart disease. Large scale studies and case reports have reported the clinical utility of MRI for diagnosis of acute and scar infarcts.

MRI is evolving at a rapid pace. Among numerous interesting developments in the sensitivity and diagnostic accuracy of MRI, many can be expected to be directly useful for the evaluation of ischemic heart disease. As hardware and coil technology are improving, image quality and diagnostic yield will be more consistent for small and focal areas of myocardial microinfarction, inflammation and fibrosis. The new MRI sequences provide early recognition of cardiac disease, and important new insights into efficacy of novel therapeutics that are currently in trails. For example, Kwong et al. [31] reported that even small infarct (1.4\% of LV mass) identified on DE-MRI portended a > sevenfold increased risk for major adverse cardiac events. Bodi et al. [22] found that assessment of infarct and microvascular obstruction on MRI soon after ST-segment elevation myocardial infarct (STEMI) enabled the prediction of reverse remodeling.

\section{Myocardial Viability}

Inversion recovery techniques, such as gradient echo and modified Look-Locker (MOLLI), are used to visualize, quantify and map myocardial infarct (MI), microvascular obstruction (MVO) and peri-infarct zone, while dynamic contrast enhanced MRI with blood pool contrast media is used to estimate blood volume and characterize vascular permeability. The most commonly used DE-MRI sequence for myocardial viability is 2D inversionrecovery gradient echo sequence (2D IR-GRE) [32]. DE-MR images are acquired 8 - $10 \mathrm{~min}$ after injection of (0.1 - $0.2 \mathrm{mmol} / \mathrm{kg}$ ) extracellular gadolinium-chelates (Figure 1). The LV mass and extent of microinfarct are quantified using semiautomatic threshold methods [15] [29] [33] [34]. The recently developed delayed contrast enhanced three-dimensional (3D) IR-GRE has been validated against 2D IR-GRE in patients with AMI [35]-[37] and in swine hearts subjected to microinfarction. The modalities provided similar estimation of large infract and microinfarct [38].

A previous DE-MRI clinical study demonstrated a large variation in the size of microinfarct $(0.7-12.2 \mathrm{~g}$ or $0.4 \%-6.0 \% \mathrm{LV}$ ) [12]. In an experimental DE-MRI study, investigators found a positive correlation between 


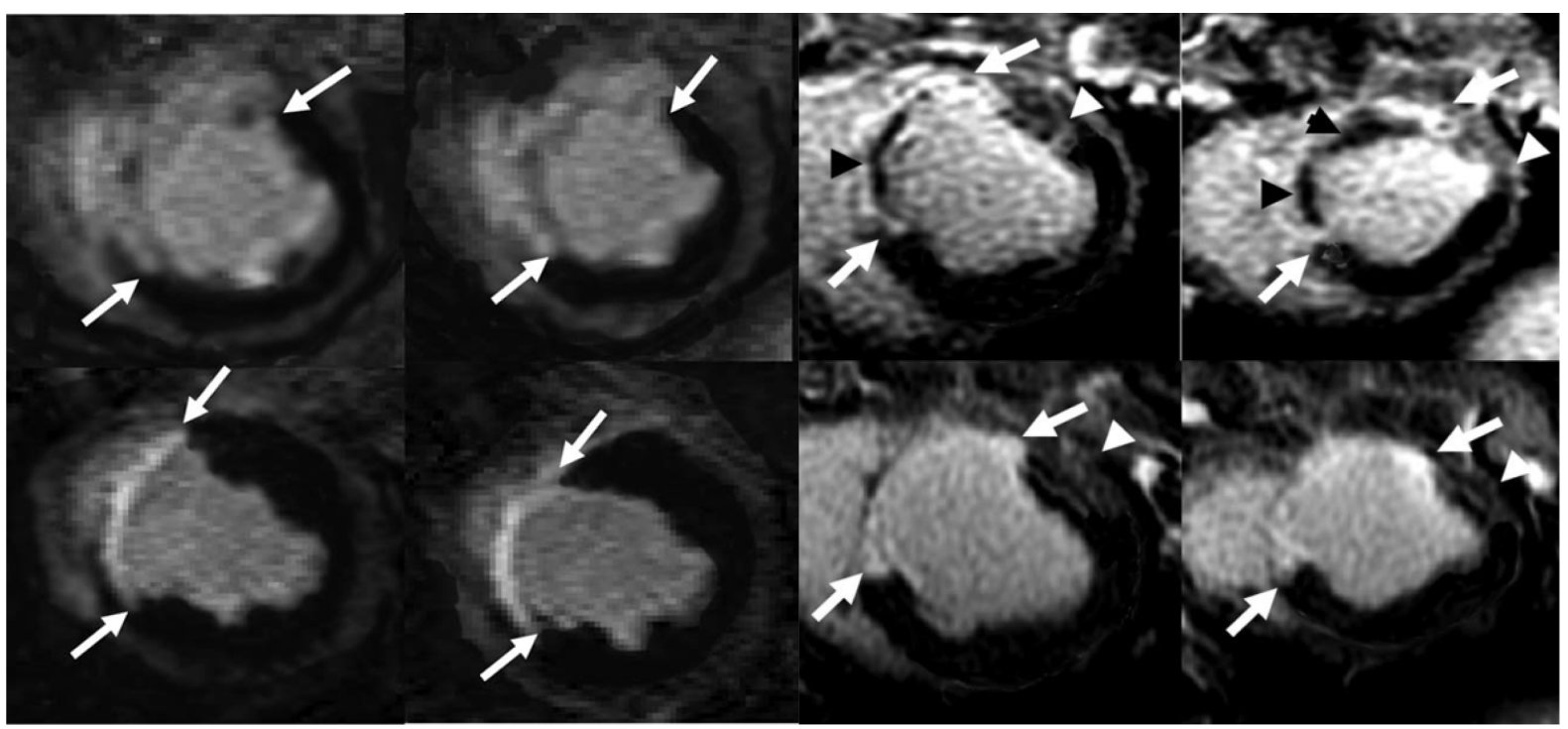

(a)

(b)

Figure 1. (a) DE-MR images obtained from an animal subjected to 90 min LAD occlusion/revascularization show hyperenhanced contiguous AMI (top row, white arrows) with small MVO zones at 3 days post intervention and hyperenhanced, thin scar infarct at 5 weeks (bottom row, white arrows) with compensatory hypertrophy in remote myocardium. (b) The images obtained from an animal subjected to $90 \mathrm{~min}$ LAD occlusion/microembolization/revascularization show hyperenhanced contiguous AMI (top row, white arrows), hypoenhanced large MVO in the core (black arrowheads) and patchy microinfarct in the border zone (white arrowheads) also 3 days post intervention. At 5 weeks, larger scar infarct and compensatory hypertrophy was evident (bottom row, white arrows) in the 90 min LAD occlusion/microembolization/revascularization animal compared with 90 min LAD occlusion/revascularization animal.

microemboli volume and microinfarct size 3 days after embolization [33]. From a clinical perspective, patchy microinfarct in the peri-infarct zone is of pivotal importance for the prognosis and recovery of LV function and arrhythmia [38] [39]. An electrophysiological study implicated the heterogeneity of depolarization and dispersion of repolarization to microinfarct within the peri-infarct zone. Investigators found that microinfarct in the peri-infarct zone is the key substrate in arrhythmia-related sudden cardiac death [40].

In a swine model, delivery of $66 \mathrm{~mm}^{3}$ microemboli also caused arrhythmia and 25\% mortality rate within the first 24 hrs [41] and this mortality rate is comparable to that observed in 90 min LAD occlusion/revascularization animals [42]. Experimental DE-MRI study demonstrated the patchy myocardial enhancement 6 hrs after microspheres injection [33] [43] [44]. Breuckmann et al. [43] indicated that a threshold of 5\% was necessary for visualization of microinfarct on DE-MRI. Furthermore, investigators reported that only visualized microinfarct on DE-MRI cause LV dysfunction in patients [45] (Figure 2). Our MRI study showed that both visible and invisible microinfarct resulted in LV dysfunction [34] because this imaging modality underestimates microinfarct size compared to microscopy.

In a recent proof-of-concept study, we demonstrated that mildly injured myocardium subjected to 40 min LAD occlusion then microembolization did not manifest greater susceptibility to infarction compared with solely embolized non-ischemic myocardium and 40 min LAD occlusion groups [15] (Figure 3).

The area at risk corresponds to the perfusion bed of embolized artery and myocardial salvage index is area at risk minus microinfarct divided by area at risk. Breuckmann et al. [43] reported that T2-weighted imaging was limited in detecting edematous area at risk $8 \mathrm{hrs}$ after embolization. They attributed this limitation to the small difference (10\%) in water content between embolized and remote myocardium [30]. More recently, T2-MRI for measurement of area at risk, based on the formation of interstitial edema, has been seriously criticized and disputed [46]. In a recent publication in patients and animals, Kim et al. [47] indicated that T2-weighted MRI did not measure salvageable myocardium, but true infarct.

The equilibrium state of distribution of MRI contrast media in myocardium can be used for evaluating myocardial viability based on the measurement of extracellular volumes. The distribution of MRI contrast media in normal myocardium is in the intravascular and interstitial spaces, while in infarcted myocardium, the myocyteslose their 


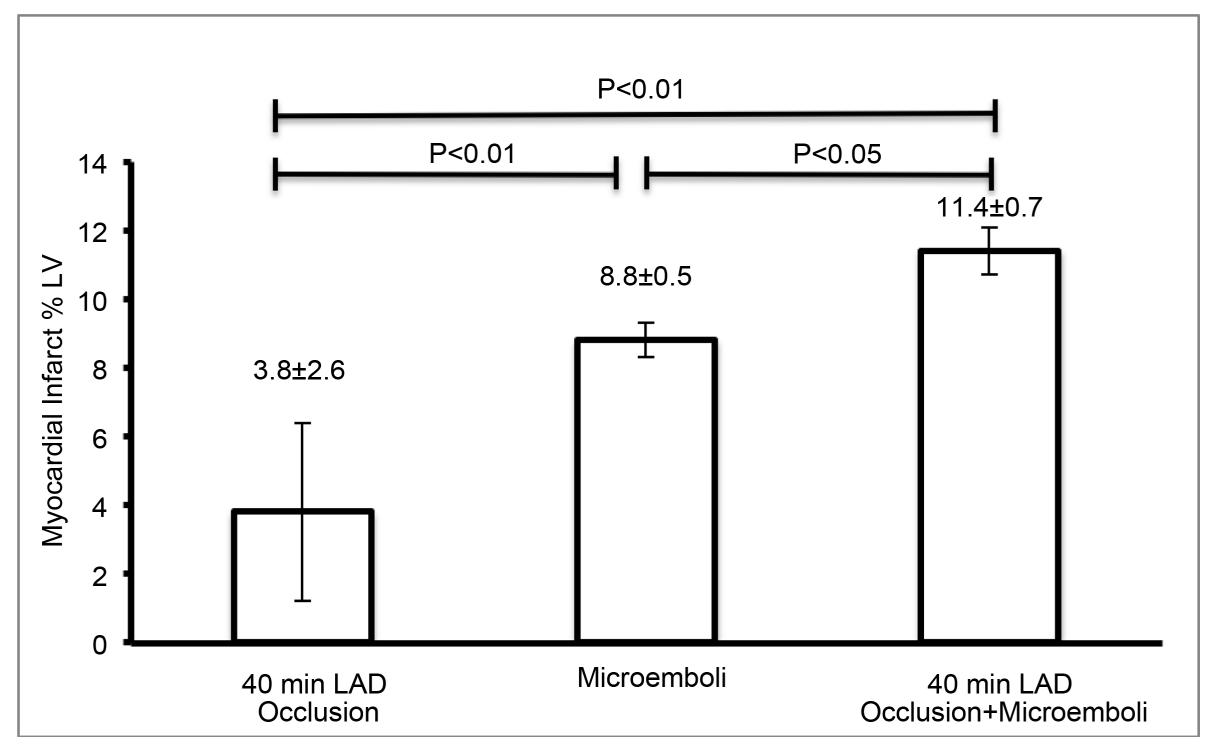

Figure 2. Bars show the incremental increase in myocardial infarct sizes in animals subjected to 40 min LAD occlusion/revascularization, coronary microembolization by $32 \mathrm{~mm}^{3}$ microemboli or the combination of both insults.

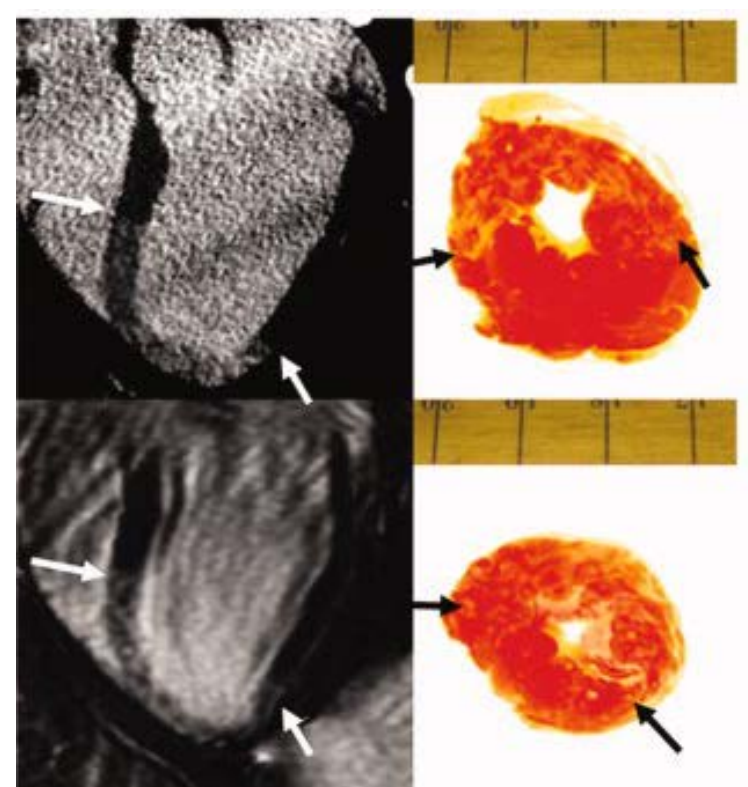

(a)

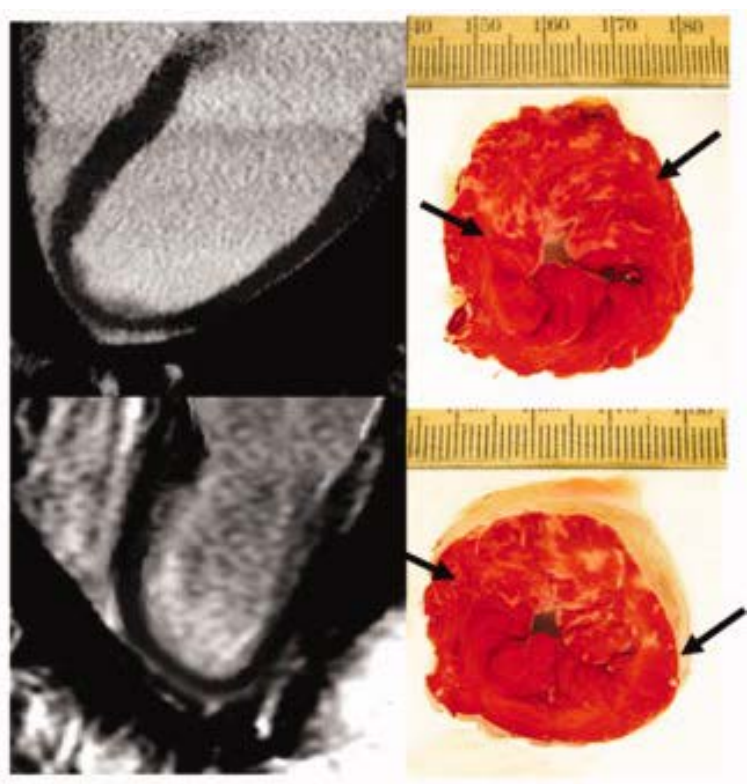

(b)

Figure 3. The variability in visualizing myocardial microinfarct on long-axis DE-MDCT (top) and DE-MR (bottom) images in two animals after administration of the same volume/sizes of microemboli $\left(16 \mathrm{~mm}^{3}\right.$ of $\left.40-120 \mu \mathrm{m}\right)$. DE-MDCT and DE-MR long-axis view images show speckled microinfarct along the inter-septal LV wall ((a) white arrows), but not (b) side images. Unlike MDCT and MRI, TTC-stained sections show microinfarct in both animals (black arrows).

cellular integrity to become a part of the extracellular space, thus providing larger distribution volume compared with normal myocardium. The technique was first used in detecting small myocardial damage in rats subjected to $20 \mathrm{~min}$ LAD coronary artery occlusion/revascularization. Investigators found clear difference in fractional distribution volume between normal myocardium (18\%) and patchy infarcted myocardium (32\%). Ischemic myocardium demonstrated dispersed focal cellular necrosis involving $18 \%$ of the cells per field under microscope [48].

The recent advancements of high field MR scanners and sequences for mapping T1 relaxation time allow scientists and clinicians to explore minor pathologic changes in myocardium. Investigators showed that $\mathrm{T} 1$ 
mapping sequences had the potential to demonstrate regional T1 changes associated with edema and diffused fibrosis [49]-[55]. T1- and T2-mapping images showed increases in native T1- and T2-relaxation times and a decrease in T1-relaxation time in MI post-contrast media injection [55] [56]. Native T1-mapping drew more attentions of clinicians, as it did not require contrast media and was accessible in the context of renal impairment or contrast allergies [56] [57].

\section{Multi-Detector Computed Tomography}

With the improvements in spatial and temporal resolution sand reduction in radiation exposure, MDCT has evolved into major clinical noninvasive coronary artery imaging modality. MDCT has been used for visualizing microinfarct and detecting LV dysfunction in embolized myocardium in beating swine heart model [41] [58][60].

Iodinated contrast media for MDCT have extracellular distribution, thus theoretically, their kinetics is parallels to those of gadolinium chelates. On the basis of this hypothesis Jablonowski et al. [60] assessed myocardial extracellular volumes in normal myocardium, contiguous infarct and patchy microinfarct. They found that the fractional distribution volume was $24 \%$ in viable myocardium, 36\% in microinfarct after delivery of $16 \mathrm{~mm}^{3}$ microemboli, $41 \%$ in microinfarct after delivery of $32 \mathrm{~mm}^{3}$, 55\% in large infarct after 90 min LAD occlusion/revascularization and 56\% after $90 \mathrm{~min}$ LAD occlusion/revascularization with delivery of 32-mm ${ }^{3}$ microemboli. The microscopic measurements confirmed MDCT data. Regression analysis revealed excellent correlation between regional myocardial extracellular volume on MDCT and microscopy $\left(r^{2}=0.92\right)$. On micro-CT, Malyar et al. identified in vitro the patchy pattern of perfusion in microembolized myocardium and attributed it to a random distribution and clustering of microemboli in microvessels [61]. However, computed tomography has limitations, such as poor temporal resolution, artifacts, radiation exposure and contrast-induced nephropathy.

\section{LV Function}

Accurate assessment of LV function is essential for the diagnosis, therapeutic management and prognosis. LV remodeling is characterized by alterations in myocytes and extracellular matrix resulting in alteration geometry and architecture of the chamber. Deformation pattern based on radial, circumferential and longitudinal myocardial strains have been used to determine the severity of myocardial dysfunction. Two-dimensional echocardiography with Doppler is the common method for assessing regional and global function of the LV. However, echocardiographic measurements present with several limitations, mainly with regard to through-plane motion and poor acoustic windows.

MRI offers great advantage over echocardiography by providing a set of contiguous short-axis MRI LV and RV slices from the base to the apex, and long-axis views. The ECG-triggered cine MRI sequences provide data on cardiac mass, volumes, and 3-D strains (radial, circumferential and longitudinal) after microembolization [29] [33] [62]-[64]. Such data can be combined with myocardial perfusion, viability and coronary flow.

Carlsson et al. [62] demonstrated the deleterious effects of relatively large microemboli (100 - $300 \mu \mathrm{m}$ diameter, $70 \mathrm{~mm}^{3}$ ) on regional LV radial strain in swine model. Cine MRI showed the changes in LV volumes and ejection fraction at 1 hour and 1 week after microembolization compared to baseline, which might be attributed to the persistent decline in the radial strain of the embolized region (Figure 4). In another study, a decline in ejection fraction from $49 \% \pm 1 \%$ at baseline to $29 \% \pm 1 \%$ at $1 \mathrm{hr}(P=0.02)$ and $36 \% \pm 1 \%$ at 1 week after delivery of 7500 microemboli of 100 - $300 \mu \mathrm{m}$ diameter was documented [63]. There was no correlation between the ejection fraction and microinfarct size $(r=0.20)$ at $1 \mathrm{hr}$ or at 1 week $(r=0.54)$. Similarly, there was no correlation between the ejection fraction and the extent of perfusion deficit at $1 \mathrm{hr}(r=0.27)$ or 1 week $(r=0.39)$ $(P=$ not significant for all). Our findings of persistent declines in regional and global functions at 1 week using relatively large emboli (100 - $300 \mu \mathrm{m}$ in diameter) are in line with findings in sheep using $90 \mu \mathrm{m}$ emboli [65]. However, heterogeneity among studies exists. For example, a study in dogs showed that LV dysfunction occurred within hours after delivering of a small embolic agent $(42 \mu \mathrm{m})$ followed by a complete recovery of function within 5 - 6 days [27]. The investigators suggested that the decrease in function resulted from myocardial inflammation mediated by TNF- $\alpha$.

We also compare the effects of two microemboli volumes (16 and $32 \mathrm{~mm}^{3}$ ) on regional and global function. We also found that the effect of $32 \mathrm{~mm}^{3}$ microemboli on radial stain was broader (involved at least 4 segments 


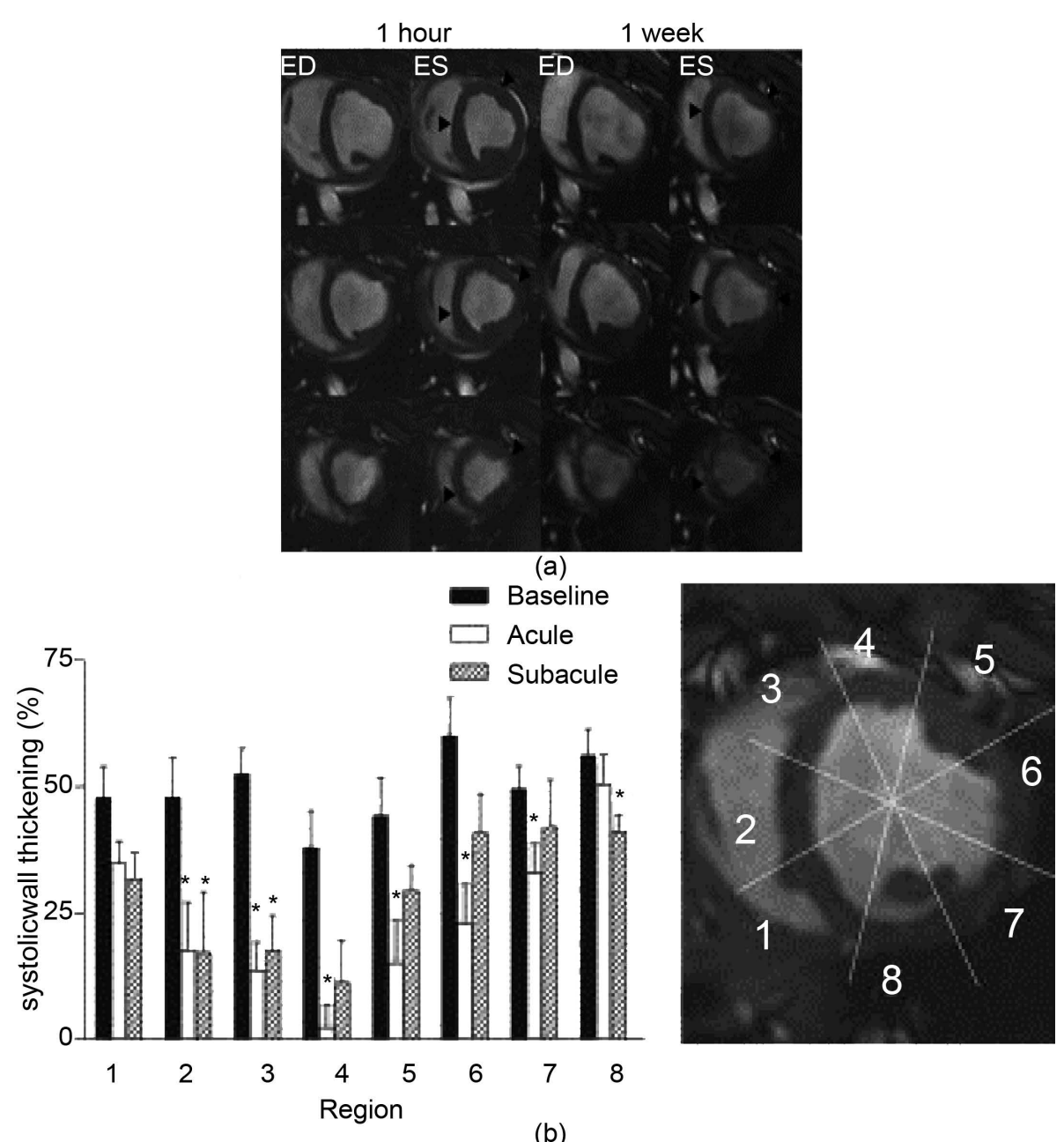

Figure 4. (a) Three slices cine MRI at $1 \mathrm{~h}$ and 1 week after microembolization acquired at end diastole and end systole. Decreased function is seen in the anteroseptal wall (black arrowheads). (b) Radial strain (systolic wall thickening) is shown in eight segments at baseline, $1 \mathrm{~h}$, and 1 week. The area of microembolization is located between segments 2 and 5 and shows dysfunction. The MR image (b) shows the location of the regions used for analysis of wall thickening. ${ }^{*} P<0.05$ compared to baseline.

in basal, mid and apical MRI slices) than animals that received $16 \mathrm{~mm}^{3}$ microemboli. At the global level, microemboli caused acute increases in LV diastolic and systolic volumes (Figure 5). Furthermore, LV ejection fraction was significantly lower in animals that received $32 \mathrm{~mm}^{3}$ than $16 \mathrm{~mm}^{3}$ microemboli [34]. Serial MRI studies showed that coronary microembolization led to LV remodeling and persistent decline in systolic wall thickening [41] [63] [66] [67].

We also explored the potential of cine MRI for quantifying the acute (3 days) effects of defined microemboli volumes and sizes on LV function in preexisting AMI in a swine model [34]. Animals subjected to LAD occlusion/microembolization/revascularization showed greater LV wall thinning, decrease in ejection fraction and increase in end-systolic volume than controls and animals subjected to LAD occlusion/revascularization (Figure 6). Quantitative analysis showed a total of 576 segments with systolic wall thickening were graded as normal, with a thickening of more than $30 \%$ (192, 112, and 64 segments in control, LAD occlusion/revascularization, and microemboli in preexisting AMI groups, respectively); hypokinetic, with 10\% - 29\% thickening (48 and 48 segments in LAD occlusion/revascularization, and microemboli in preexisting AMI groups, respectively); akinetic, $0 \%-9 \%$ (32 and 32 segments, respectively); and dyskinetic, $-10 \%$ to $0 \%$ ( 0 and 48 segments, respectively). Dyskinesis and paradoxical systolic-wall thinning were observed only in LAD occlusion/microembolization/revascularization group. Circumferential and longitudinal wall strains were also depressed after coronary 


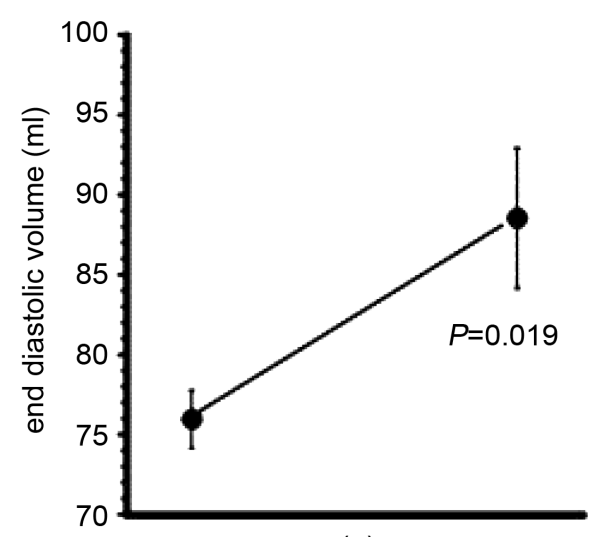

(a)

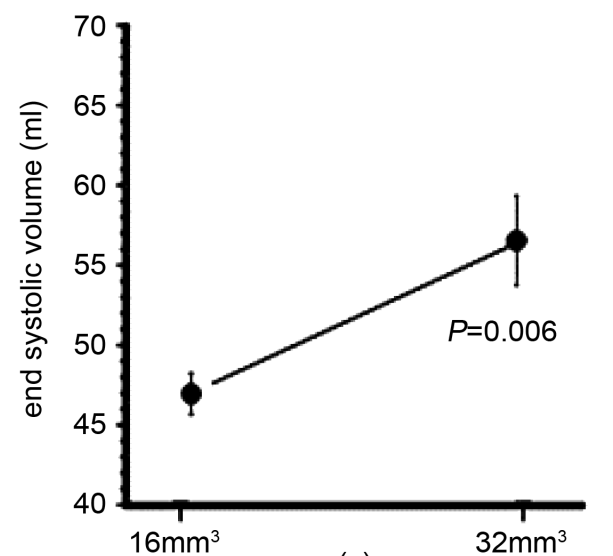

(c)

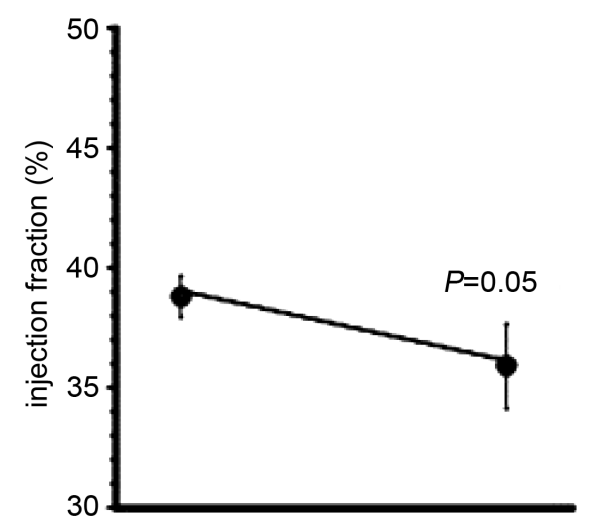

(b)

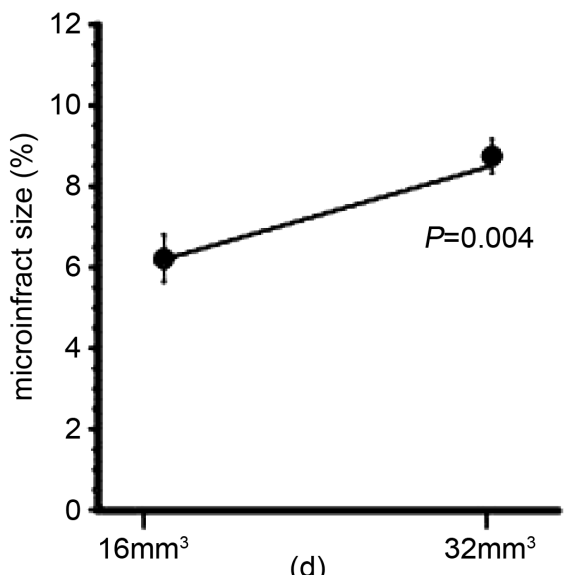

(d)

Figure 5. The effects of two different microemboli volumes are shown on LV end diastolic volume (a), end systolic volume (c), ejection fraction (b) on cine MRI and speckled enhanced microinfarct size (d) on DE-MRI. All the parameters show significant difference related to the microemboli volumes.

microembolization [64]. Suhail et al. [64] found that cine and tagged MRI sequences were useful for measuring left/right ventricles longitudinal and circumferential strains in patchy microinfarct and large infarct, respectively. HARP and plane metric software are used to quantify circumferential and longitudinal strains in microembolized infarct. Investigators observed that coronary microemboli caused greater impairment in LV circumferential strain and dyssynchrony than 90 min LAD occlusion/revascularization animals despite the significant differences in infarct sizes. Microemboli also caused a significant decrease in peak systolic strain rate of remote myocardium and LV dyssynchrony. Compensatory increase in longitudinal strain of RV free wall was also observed in response to microemboli delivered in the LAD and LAD occlusion/revascularization animals. This study concluded that 1) coronary microemboli with or without AMI core caused complex myocardial injury and ventricular dysfunction that were not replicable in solely AMI and 2) there was a disproportion in the declines of circumferential strain, dyssynchrony, and infarct size of animals subjected to microembolization and AMI. Clinical study showed that longitudinal strains measured on cine MRI correlated well with infarct sizes [68], while Galiuto [69] indicated that the improvement in longitudinal strain was an index of myocardial viability, associated with global LV improvement and possibly reverse remodeling, which is an important predictor of a favorable long-term outcome.

\section{Myocardial Perfusion}

The severity and extent of myocardial ischemia is a key to decision-making for revascularization. With commencing myocardial ischemia, a cascade of cellular, functional and electrocardiographic events ensues. Thallium-201 scintigraphy studies demonstrated that coronary stenos is causes perfusion deficits [70] [71]. Investigators also observed a mismatch between LV dysfunction and epicardial coronary blood flow after revascularization 


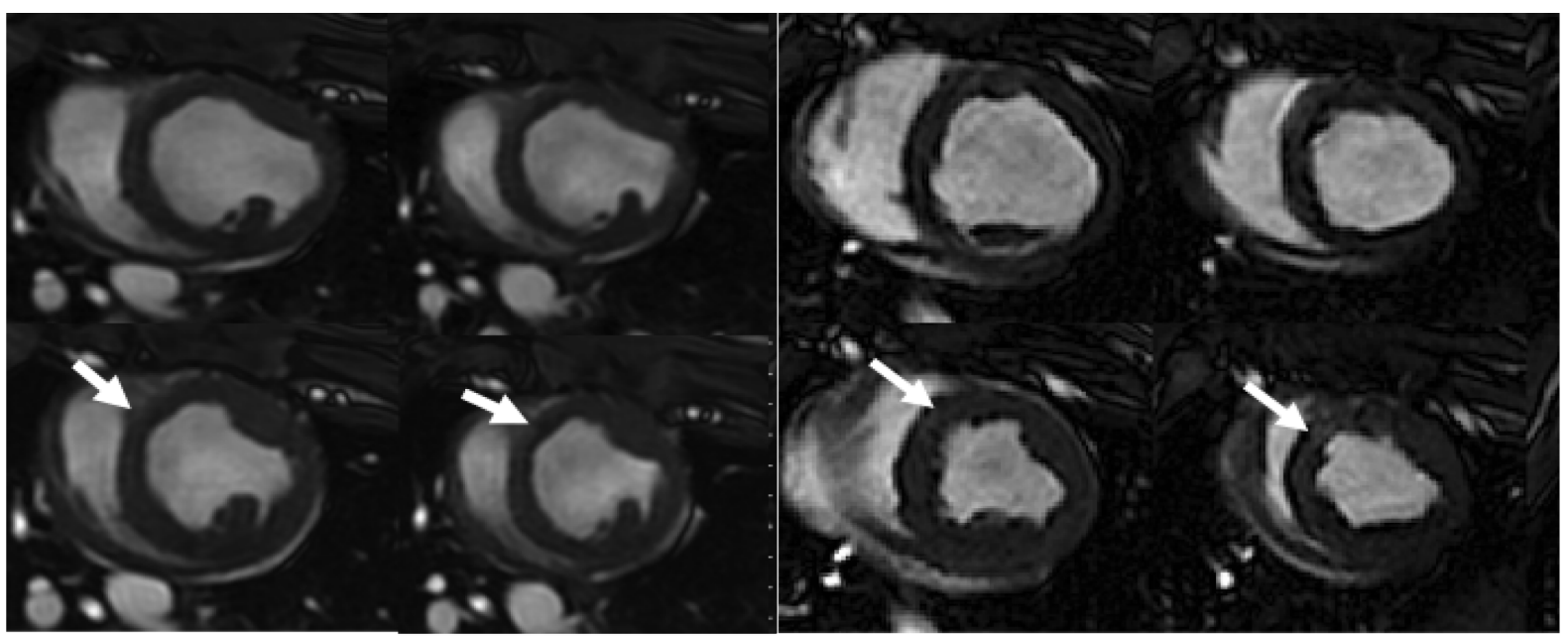

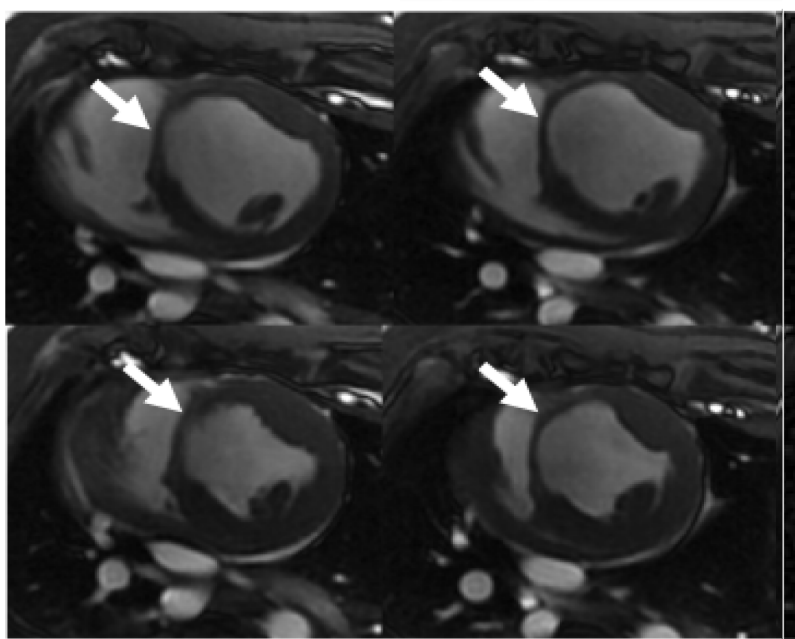

(a)

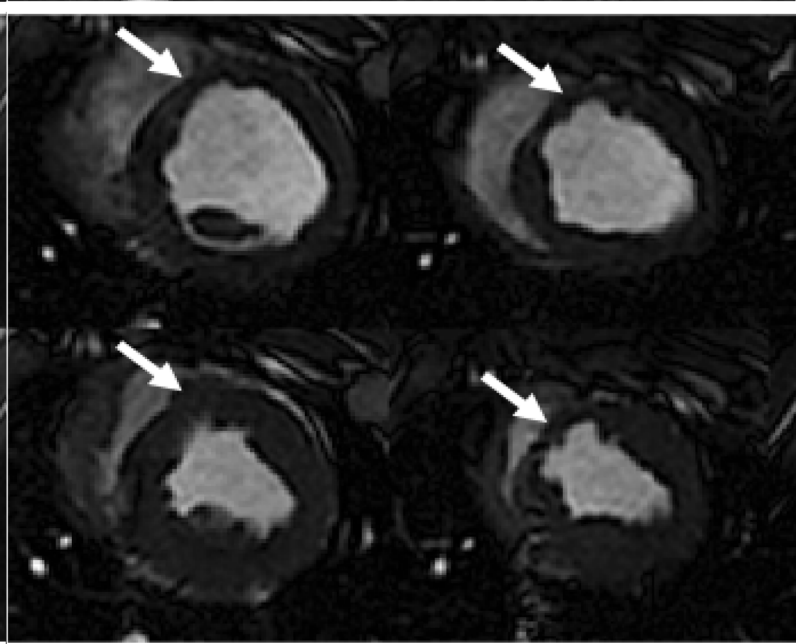

(b)

Figure 6. Cine MRI. (a) Multislice diastolic (top row) and systolic (bottom row) cine MR images acquired at 3 days (top block) and 5 weeks (bottom block) from an animal subjected to 90 min LAD occlusion/revascularization. White arrows point to the site of infarction and show wall thinning at 5 weeks. (b) Multislice diastolic (top row) and systolic (bottom row) cine MR images acquired at 3 days (top block) and 5 weeks (bottom block) in an animal subjected to 90 min LAD occlusion/microembolization/revascularization. At 5 weeks, the site of infarction (arrows) show greater wall thinning compared with 90 min LAD occlusion/revascularization.

[72]. First pass MRI also detected myocardial perfusion deficits in patients after PCI [24] [73].

In general, microembolized myocardium with and without pre-existing infarct is defined as hypoenhanced zone on first pass MRI. Unlike DE-MRI, perfusion imaging has the potential to detect early effect of microemboli (as early as $1 \mathrm{hr}$ ) on myocardium perfusion (Figure 7). Maximum upslope, maximum SI and time to the peak obtained from first pass MRI perfusion are the best indices to estimate regional perfusion deficits [33] [34] [62] [74]. Quantitative analysis of perfusion parameters revealed in these studies that the maximum signal intensity and time to peak were lower and longer, respectively, in both acute and scar microinfarct compared with remote myocardium. Selvanayagam et al. [75] used first pass perfusion and DE-MRI to demonstrate perfusion deficits and new microinfarct 24 hrs after PCI. Choi et al. [45] found an association between perfusion deficits and discrete AMI in patients after PCI.

In an experimental study, Mohlenkamp et al. [76] investigated the changes in coronary microcirculation (intramyocardial microvascular blood volume, perfusion, transit time and pattern of microvascular injury) in response to different sizes of microemboli. They observed that $100 \mu \mathrm{m}$ microspheres resulted in patchy plugging, while $10 \mu \mathrm{m}$ microspheres induced contiguous hemorrhagic myocardial injury. Skyschally et al. [73] demonstrateda lack of changes in baseline coronary blood flow after stepwise repeated injections of microsphere (42 


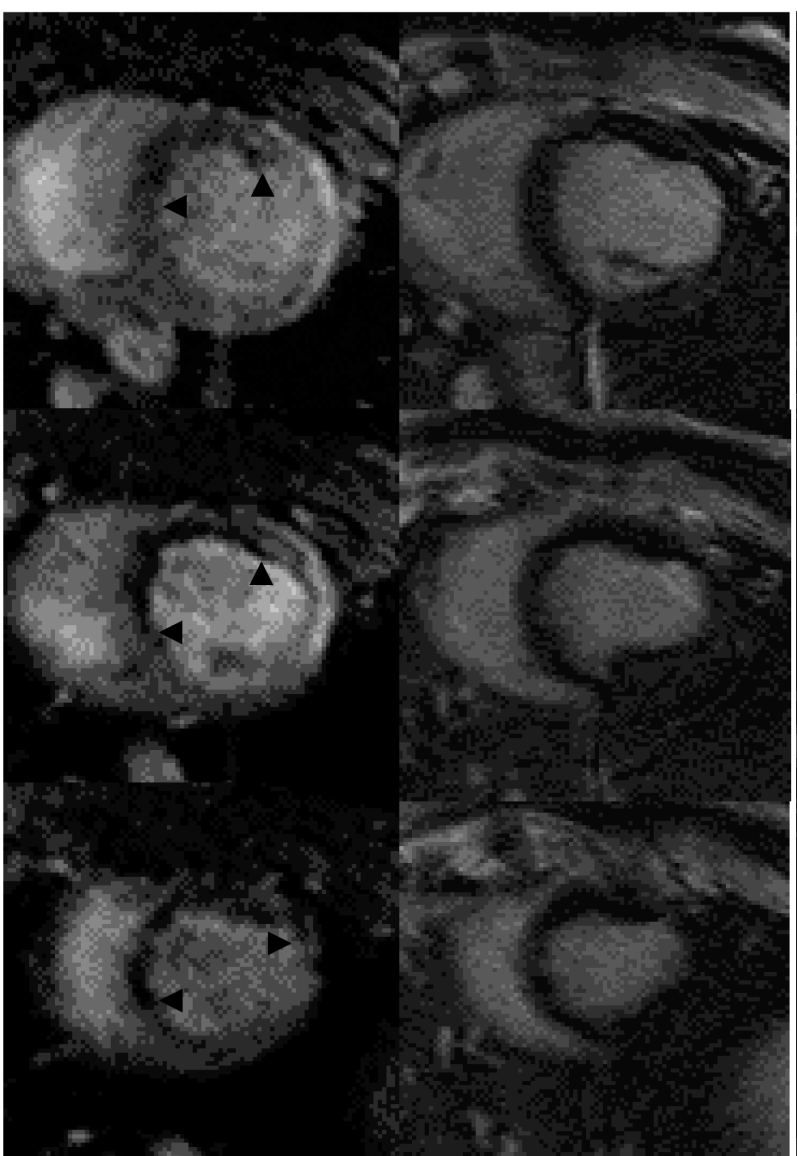

(a)

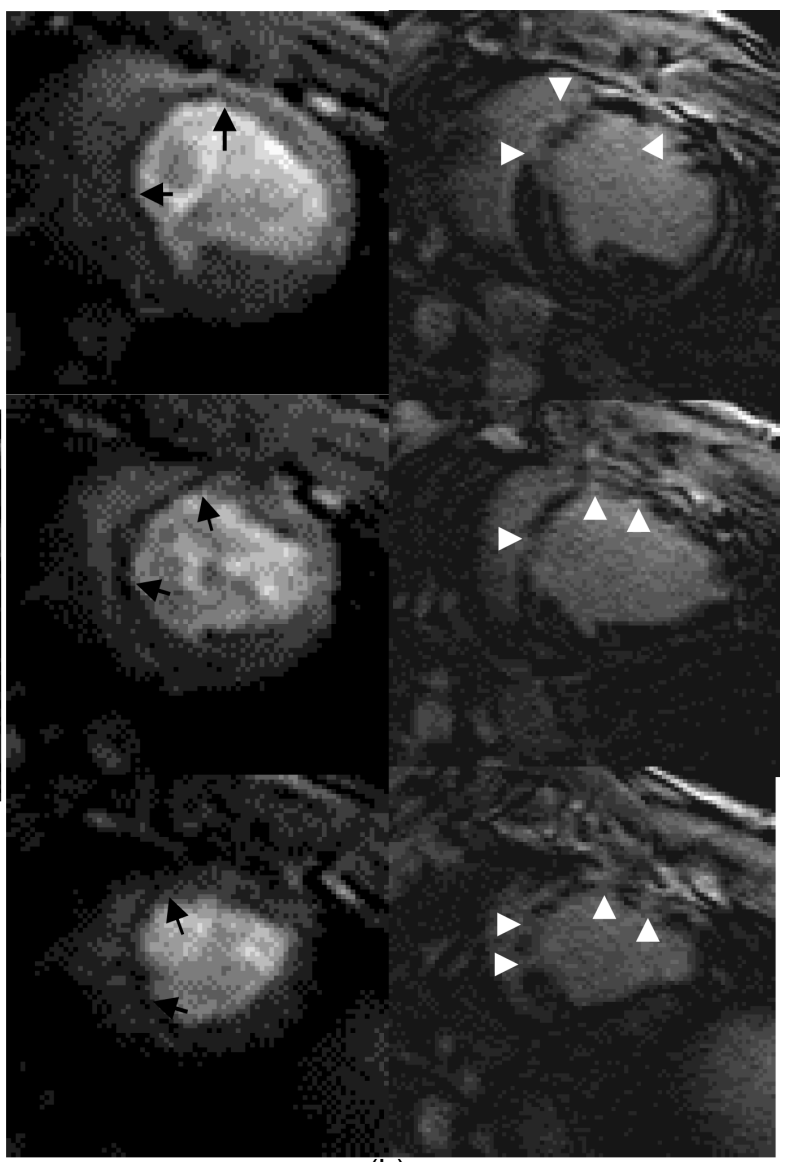

(b)

Figure 7. Multislice first pass perfusion DE-MR images acquired $1 \mathrm{hr}$ ((a), left block) and 1 week ((b), right block) after LAD embolization show the persistent perfusion deficit in embolized myocardium. DE-MRI images acquired $1 \mathrm{hr}$ after embolization failed to demonstrate myocardial microinfarct. On the contrary, DE-MRI provided evidence of microinfarct at 1 week.

$\mu \mathrm{m}$ diameter) using Doppler flowmeter. In contrast, Ma et al. observed in swine the reductions in coronary flow reserve and LV ejection fraction 6 hours after emboli injection $(42 \mu \mathrm{m}, 120,000)$ into LAD. The animals showed complete recoveries of flow reserve and LV ejection fraction, but LV dilation, 1 week later [66]. Bai et al. [77] also reported a persistent LV dysfunction and progressive remodeling in swine model 28 days after repeated microsphere injection.

\section{Histopathology}

Gu et al. [8] observed under light and electron microscope that delivery of automicrothrombotic particles into the coronary arteries induced microthrombosis, damage of vascular endothelium, and microinfarct. Other investigators showed that monocytes/macrophages dominated the cellular infiltrates for the first 2 weeks after MI and participated in wound healing [78] [79]. Frangogiannis [80] classified the healing process of myocardial infarct into 3 distinct but overlapping phases: the inflammatory phase, the proliferative phase, and the maturation phase, while Nahrendorf et al. [81] summarized the roles of monocytes/macrophages in infarct healing, including 1) release inflammatory mediators; 2) release proteases; 3) phagocytose apoptotic and necrotic myocytes and neutrophils and other debris; 4) promote angiogenesis; 5) transport reparative enzymes and prosurvival factors; and 6) stimulate collagen synthesis and deposition by myofibroblasts. It has been shown that multiple injections of microspheres also induce myocardial injuries similar to those seen in patients after revascularization [77]. Figure 8 shows the patchy microinfarct and infiltration of inflammatory cells in infarcted myocardium 3 days after microembolization. Dead myocytes were generally found in clusters (large or small). Furthermore, microinfarcts 


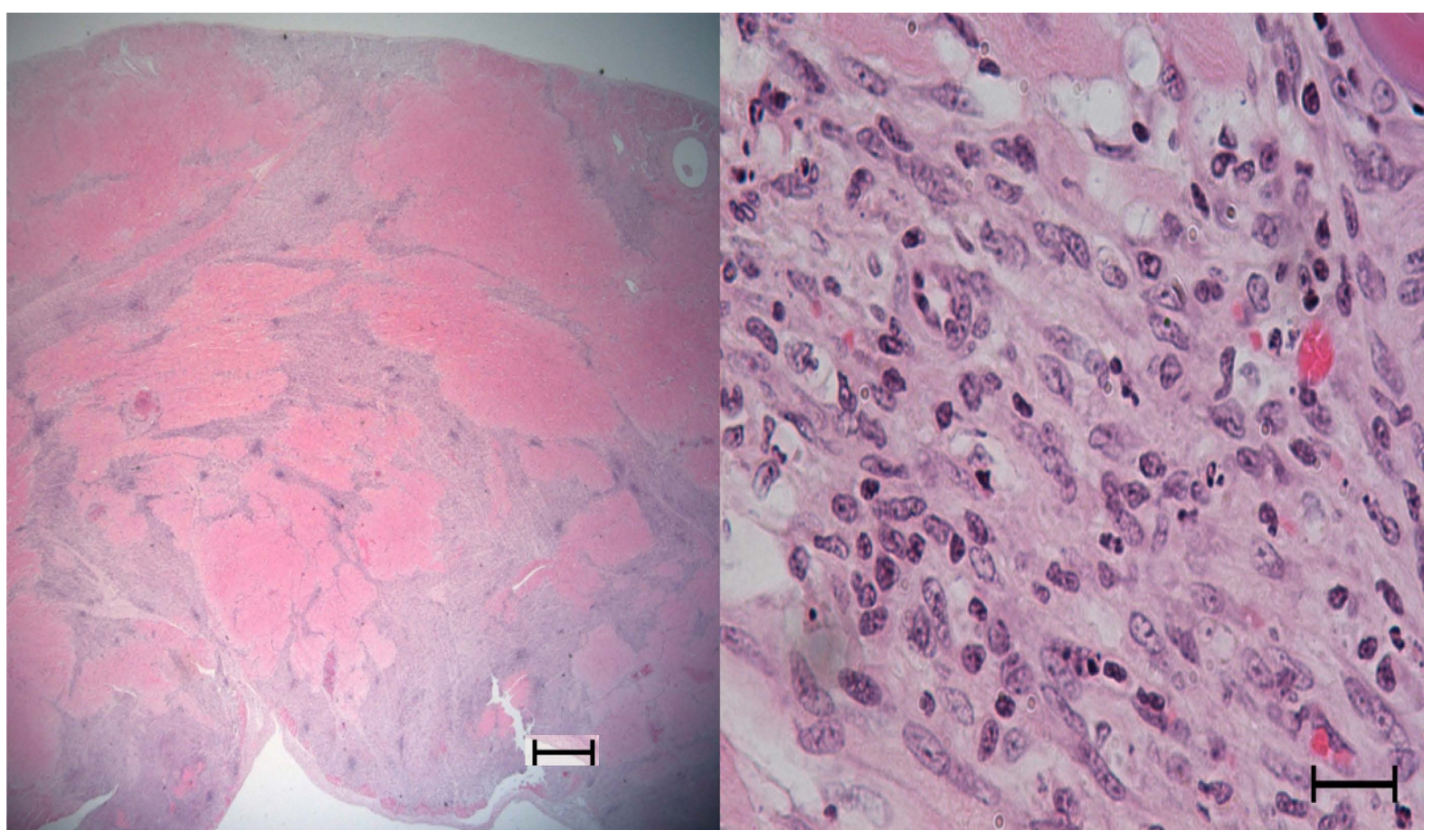

Figure 8. Microscopic cardiac sections stained with hematoxylin-eosin show the patchy microinfarc and infiltration of inflammatory cells in infarcted myocardium 3 days after coronary microembolization $(10 \times$, scale $=500 \mu \mathrm{m}$ and $100 \times$, scale $=$ $50 \mu \mathrm{m})$.

showed severe coagulation and a contraction band of necrosis with complete loss of cellular and vascular architectures. The islands of microinfarct spread randomly within the LAD territory and were relatively small and less dense in animals that received small volume of microemboli $\left(16 \mathrm{~mm}^{3}\right)$ compared with animals that received large volume $\left(32 \mathrm{~mm}^{3}\right)$. Three days after delivery of solely emboli, necrotic myocytes were replaced with aggregates of mononuclear cells (mostly macrophages) [34]. Bai et al. [77] observed an early increased inflammatory activity followed by persistent pro-inflammatory cytokines protein expression and collagen deposition. The use of iron particles, as MR contrast medium, might be helpful in noninvasively identifying and quantifying temporal changes in myocardial inflammation [82]. Monitoring macrophages/monocytes infiltration might be useful for predicting clinical outcomes and treatment efficacy.

Gu et al. [8] observed under light and electron microscopy that delivery of automicrothrombotic particles into the coronary arteries induced microthrombosis, damage of endothelial cells and myocardial microinfarct. Others found in the first week that intravascular microemboli are surrounded by fibrin, aggregated platelets and leukocytes [58]. Scar microinfarct were microscopically differentiated from acute microinfarct by the lack of infiltration of inflammatory cells and fibrosis [15] [29] [83]. At 5 weeks, reperfused infarct without microemboli showed remodeled blood vessels with a thick wall and small lumen, but no evidence of obstructed vessels, while revascularized infarct with microemboli showed almost complete obstruction of microvessels (Figure 9). Furthermore, at this time intravascular microemboli started to cross the vascular wall and by 8 weeks they were settled in the interstitial space. Microscopy also disclosed the presence of single, multiple of various sizes of microemboli outside of the intravascular compartment (peri-vascular space) (Figure 10).

It has been shown that slow infarct healing can lead to LV remodeling, infarct rupture and death [84]. Interstitial edema was evident at 5 weeks in remote myocardium of animals subjected to LAD occlusion/microembolization/revascularization, but not in LAD occlusion/revascularization animals (Figure 11). Furthermore, these animals showed less infarct resorption and LV dilation at 5 weeks in animals subjected to LAD occlusion/microembolization/revascularization compared with LAD occlusion/revascularization animals (Figure 1). Thus, our experimental study [29] proved the conjecture by Kloner [85] and Wu [86] that MVO delayed/inhibited optimal infarct healing by slowing the delivery of inflammatory cells and nutrients. Infarct resorption (shrinkage) is related to the deposition of compact fibroblasts that have smaller sizes than cardiomyocytes. A clinical MRI 

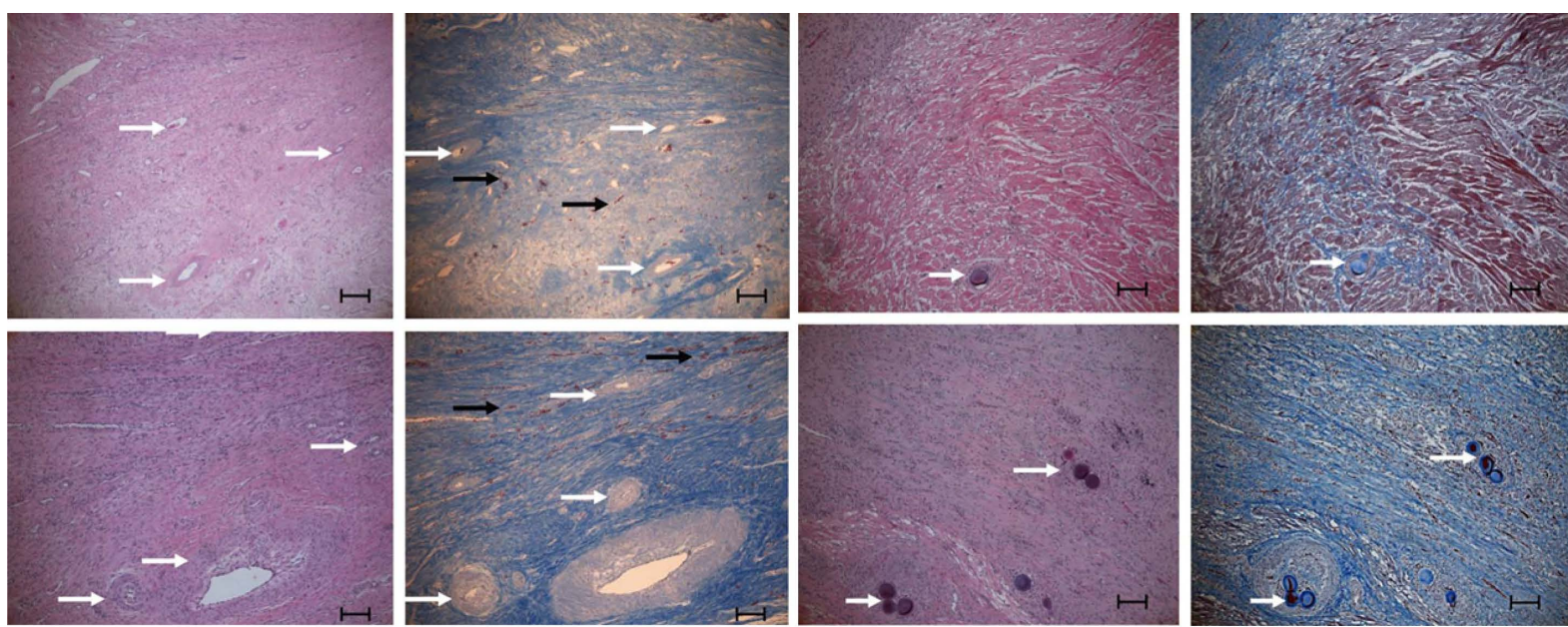

(a)

(b)

Figure 9. Microscopic cardiac sections stained with hematoxylin-eosin and Masson trichrome stains show the differences at the cellular and vascular levels between 90 min LAD occlusion/revascularization at 5 weeks (a) and 90 min LAD occlusion/microembolization/revascularization at 5 weeks (b) animals. The former animal showed remodeled blood vessels with a thick wall and small lumen (white arrows) and new patent vessels (black arrows), but no evidence of obstructed vessels. The latter animal showed complete obstruction of microvessels by fibrotic tissue, debris and inflammatory cells $(10 \times$, scale $=500$ $\mu \mathrm{m})[15]$ [29] [83].

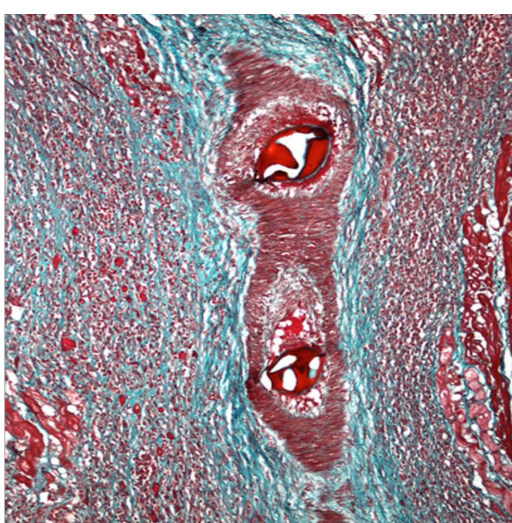

1 Week

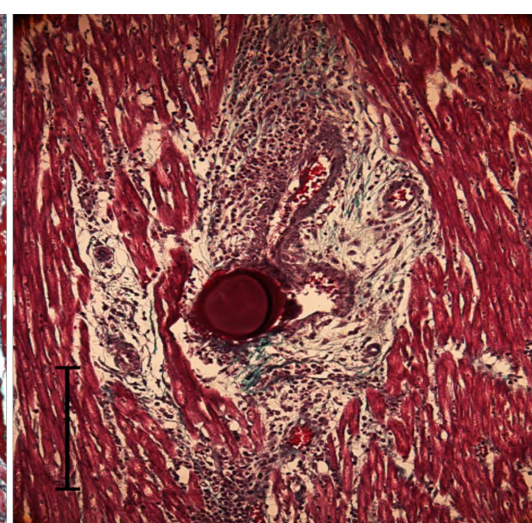

5 Weeks

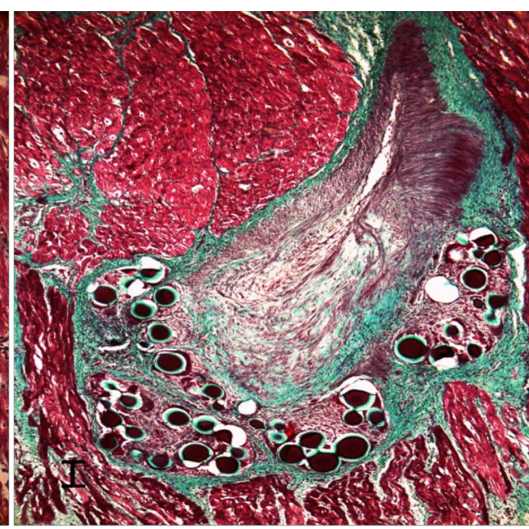

8 Weeks

Figure 10. Migration of intravascular coronary microemboli into the interstitial space as a function of time. At 5 weeks the microemboli start to migrate into interstitial space and 8 weeks almost all microemboli are located in the interstitial space. (top $\times 40$, middle and bottom $\times 200[15][83]$ ).

study showed that the resorption of large infarct was faster than small infarct [87]. On the contrary in swine, MRI and histologic study demonstrated that the resorption of microinfarct was faster than large infarct [15]. The resorption of solely microinfarct and large infarct at 5 weeks were $60 \%$ and $25 \%$, respectively, [15] [88]. Choi et al. [89] and Inkangisorn et al. [90] found in patients a decline in infarct sizes of $27 \%$ and $31 \%$, respectively, 2 months after infarction. These results indicate that the percent resorption of myocardial infarct is identical in humans and swine.

At the global level, LV mass was the greatest in animals subjected to occlusion/microembolization/revascularization compared to control and 90min LAD occlusion/revascularization animals, which is partially related to the interstitial edema (Figure 12). Additionally, scar microinfarct on DE-MRI (1.3 $\pm 0.9 \mathrm{~g})$ and histochemical staining (1.9 $\pm 1.2 \mathrm{~g})$ are smaller than on microscopy ( $3.3 \pm 0.5 \mathrm{~g}, P<0.05)$ [15] [83]. The difference in the measurements was even greater in animals subjected to LAD occlusion/microembolization/revascularization compared with animals subjected to only microembolization $(9.0 \pm 0.6 \mathrm{~g}$ on DE-MRI, $10.7 \pm 1.9 \mathrm{~g}$ on histochemical staining and $15.6 \pm 2.8 \mathrm{~g}$ on microscopy, $P<0.05$ ).

Investigators observed apoptotic bodies in microembolized and remote myocardium using cleaved caspase 3 


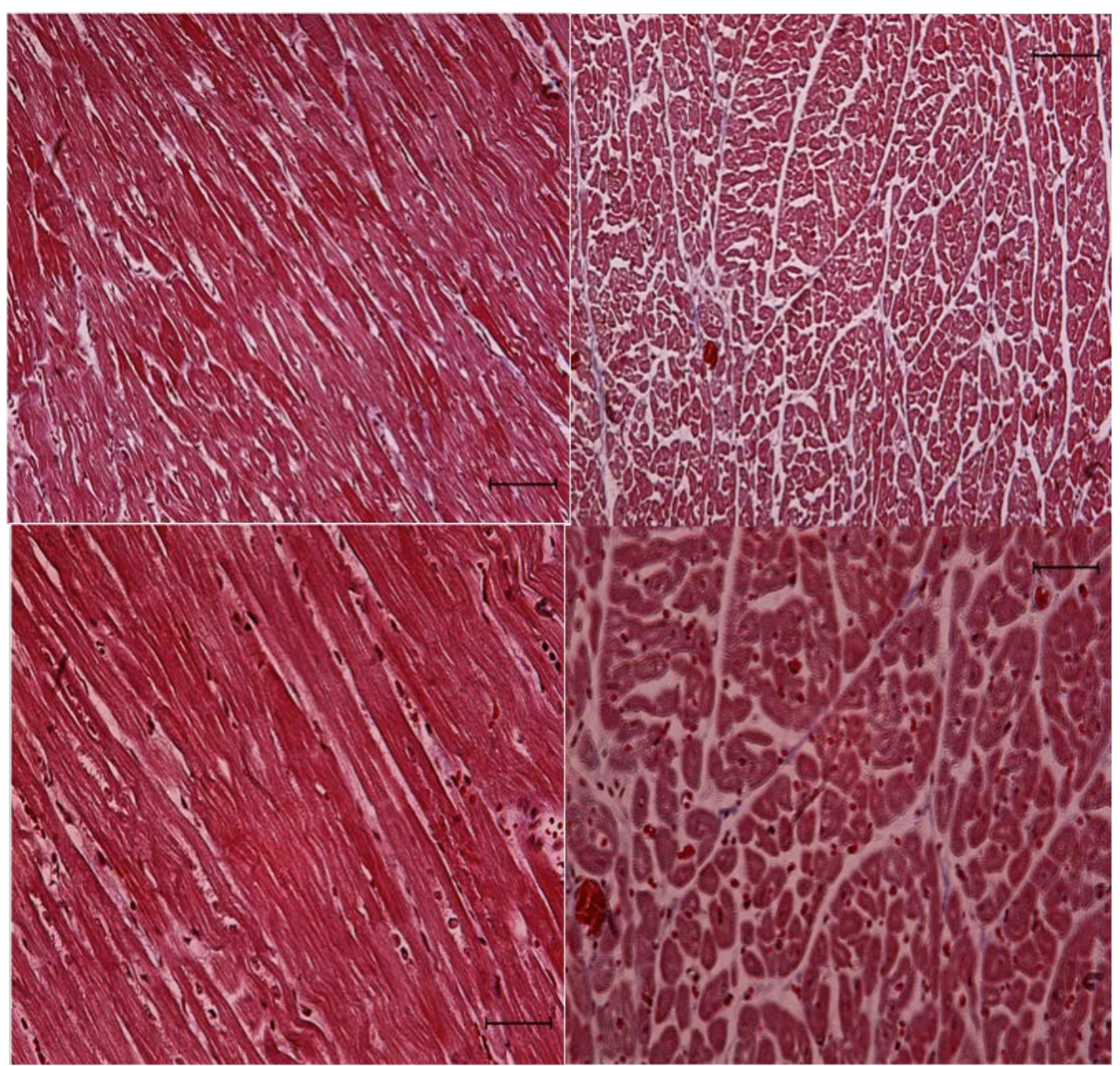

(a)

(b)

Figure 11. Microscopic sections show remote myocardium in animals subjected to 90 min LAD occlusion/revascularization (a) and $90 \mathrm{~min} \mathrm{LAD} \mathrm{occlusion/microembolization/revascularization} \mathrm{(b).} \mathrm{The} \mathrm{interstitial} \mathrm{edema} \mathrm{is} \mathrm{evident} \mathrm{only} \mathrm{in} \mathrm{LAD} \mathrm{occlu-}$ sion/microembolization/revascularization 5 weeks after the interventions $(\times 40$ and $\times 100)$.

stain [33] [91]. Reactive oxygen species have been shown to exert direct inhibitory effects on myocardial function in vivo and to have a critical role in the pathogenesis of myocardial stunning [92]. Activation of lectin-like oxidized low-density lipoprotein receptor 1-dependent mitochondrial pathway, caspase-8-dependent pathway, [93] and tumor necrosis factor $\alpha$ (TNF- $\alpha$ ) [94] induced apoptosis. TNF- $\alpha$ is a cytokine released during myocardial infarction. It's expression during the healing phase was not confined to the infarct or peri-infarct zone and could be localized in the viable remote myocardium [33] [94], in which remodeling is ongoing [29].

\section{Treatment of Myocardial Microinfarct}

Chen et al. [95] recently found that glucocorticoid therapy improved LV function after coronary embolization through the suppression of transforming growth factor-beta 1 (TGF- $\beta 1$ )/Smad 3 and connective tissue growth factor. It also attenuated LV remodeling caused by microinfarct [67]. Jin et al. [96] found a less decline in regional wall motion in the embolized area in animals treated with glucocorticoid (methylprednisone, as anti-inflammatory therapy) than control animals at 6 hrs after coronary microembolization. Methylprednisone administration ameliorated myocardial dysfunction ( $88.6 \% \pm 7.6 \%)$ compared with control group $(47.7 \% \pm 4.7 \%$; $P<$ $0.001)$ at 6 hrs after embolization. The systolic wall-thickening index was at the baseline, $96.3 \% \pm 8.2 \%$. The LV ejection fraction decreased from $49.9 \% \pm 3.5 \%$ at baseline to $34.6 \% \pm 3.7 \%$ at 6 hours $(P<0.001)$ in the 


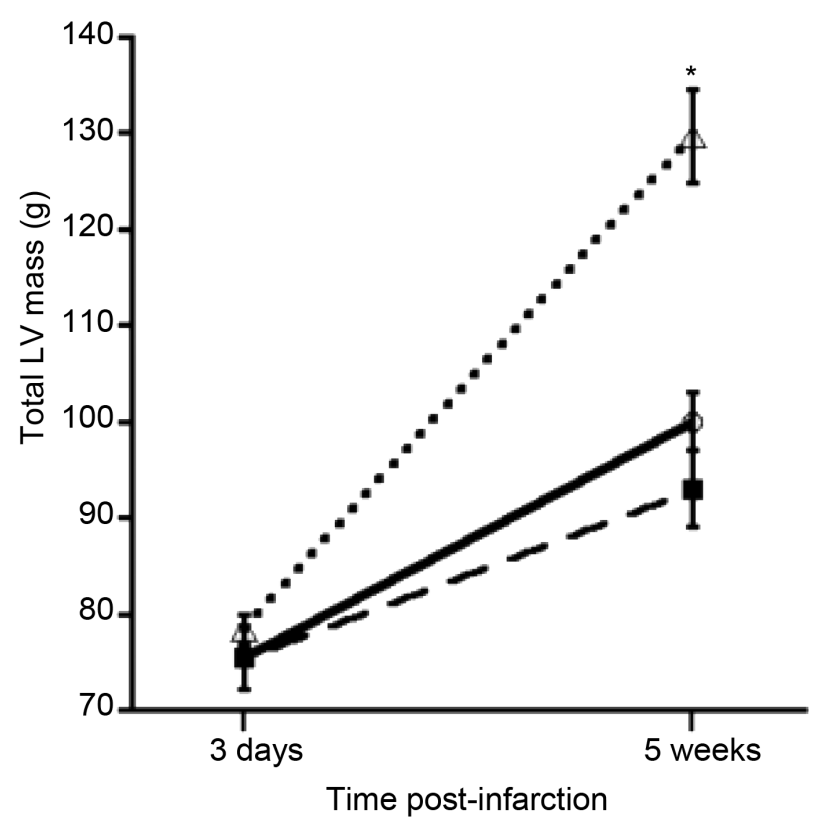

Figure 12. A plot showing the differential increase in LV masses over the course of 5 weeks in control (dashed line), 90 min LAD occlusion/revascularization (continuous line) and $90 \mathrm{~min}$ LAD occlusion/microembolization/revascularization animals (dotted line). ${ }^{*} P<0.001$ compared with the other two groups.

control group, which was significantly less in treated group from $47.1 \% \pm 3.8 \%$ to $42.5 \% \pm 3.9 \%$. Other found that statins, antiplatelet agents, and coronary vasodilators can protect AMI from microemboli and additional microinfarct when administered prior to PCI. Distal protection devices can retrieve atherothrombotic debris, but their effects are controversial.

Experimental studies revealed that the phosphatase and tensin homolog deleted on chromosome ten (PTEN) were proteins regulating inflammation and apoptosis. Apoptotic bodies were evident in microembolized and remote myocardium using cleaved caspase 3 stain [33] [91]. This protein is highly expressed in reperfused AMI and it enhances inflammation after embolization [97]. Investigators found that inhibition of PTEN improved myocardial function by attenuating myocardial apoptosis [28].

Additional observations in microembolized myocardium are: calcium deposits were also evident in scar microinfarct [33] and intravascular microemboli were present in the perivascular space 5 - 8 weeks after delivery of microemboli, suggesting migration of microemboli across vascular wall. This phenomenon may limit the use of microemboli therapy in treating tumors or occluding hemorrhagic blood vessels. Recent studies showed that emboli were cleared from the microvasculature by either hemodynamic pressure or angiophagy, in which emboli were engulfed by the endothelium and translocated through the microvascular wall [10]. Furthermore, it has been recently proposed that monitoring of coronary microvascular function might facilitate tracking injectable macromolecular nanoparticles that use the leaky vasculature after MI for infarct healing [98].

In summary, existing diagnostic algorithms for the determination of the potential etiologic substrate of coronary microembolization and myocardial microinfarction processes are largely based on the identification of myocardial ischemia/injury and inflammation. This review shows an incremental diagnostic utility of MRI in coronary microembolization and myocardial microinfarction beyond the algorithm established by current guidelines. It also adds to the existing body of information on the utility of MRI to identify potentially reversible myocardial abnormalities and to define the prognostic use of MRI for the treatment of injured myocardium. MRI has been proven to reliably assess regional perfusion and LV function of microembolized myocardium. The visibility of microinfarct on DE-MRI is limited and dependent on technical issues, such as optimization of the inversion time, elimination of motion artifacts and MR contrast media relaxation time in situ and their kinetics (wash-in/wash-out) as well as biological issues, such as microemboli volume, age of microinfarct and collateral circulation. Cardiac MRI should focus in the future on improving the spatial resolution and acquisition time to overcome some of these limitations. Additionally, for advancement of clinical care it is of paramount importance to develop innovative techniques for preventing coronary microemboli formation and treating micropin- 
farct. Microscopic examination of biopsy is a gold standard method for confirming the presence of microemboli in coronary microvessels, but biopsy is not recommended after PCI in routine clinic.

\section{Acknowledgements}

We would like to thank Carol Stillson for her excellent technical assistance in animal preparation.

\section{Conflicts of Interest}

None.

\section{References}

[1] Go, A.S., Mozaffarian, D., Roger, V.L., et al. (2014) Heart Disease and Stroke Statistics—2014 Update: A Report from the American Heart Association. Circulation, 129, e28-e292. http://dx.doi.org/10.1161/01.cir.0000441139.02102.80

[2] Moody, D.M., Bell, M.A., Challa, V.R., Johnston, W.E. and Prough, D.S. (1990) Brain Microemboli during Cardiac Surgery or Aortography. Annals of Neurology, 28, 477-486. http://dx.doi.org/10.1002/ana.410280403

[3] DeFrances, C.J., Buie, V.C. and Golosinskiy, A. (2006) National Hospital Discharge Survey, 2008. US Department of Health and Human Services Centers for Disease Control and Prevention National Center for Health Statistics Hyattsville, MD, USA.

[4] Rezkalla, S.H. and Kloner, R.A. (2002) No-Reflow Phenomenon. Circulation, 105, 656-662. http://dx.doi.org/10.1161/hc0502.102867

[5] Cuculi, F., Lim, C.C.S. and Banning, A.P. (2010) Periprocedural Myocardial Injury during Elective Percutaneous Coronary Intervention: Is It Important and How Can It Be Prevented? Heart, 96, 736-740. http://dx.doi.org/10.1136/hrt.2009.186189

[6] Nallamothu, B.K. and Bates, E.R. (2003) Periprocedural Myocardial Infarction and Mortality: Causality versus Association. Journal of the American College of Cardiology, 42, 1412-1414. http://dx.doi.org/10.1016/S0735-1097(03)01037-4

[7] Schwartz, R.S., Burke, A., Farb, A., et al. (2009) Microemboli and Microvascular Obstruction in Acute Coronary Thrombosis and Sudden Coronary Death: Relation to Epicardial Plaque Histopathology. Journal of the American College of Cardiology, 54, 2167-2173. http://dx.doi.org/10.1016/j.jacc.2009.07.042

[8] Gu, Y., Bai, Y., Wu, J., Hu, L. and Gao, B. (2010) Establishment and Characterization of an Experimental Model of Coronary Thrombotic Microembolism in Rats. American Journal of Pathology, 177, 1122-1130. http://dx.doi.org/10.2353/ajpath.2010.090889

[9] Prizel, K.R., Hutchins, G.M. and Bulkley, B.H. (1978) Coronary Artery Embolism and Myocardial Infarction: A Clinicopathologic Study of 55 Patients. Annals of Internal Medicine, 88, 155-161. http://dx.doi.org/10.7326/0003-4819-88-2-155

[10] Grutzendler, J., Murikinati, S., Hiner, B., et al. (2014) Angiophagy Prevents Early Embolus Washout But Recanalizes Microvessels through Embolus Extravasation. Science Translational Medicine, 6, 226ra31-226ra31. http://dx.doi.org/10.1126/scitranslmed.3006585

[11] Lam, C.K., Yoo, T., Hiner, B., Liu, Z. and Grutzendler, J. (2010) Embolus Extravasation Is an Alternative Mechanism for Cerebral Microvascular Recanalization. Nature, 465, 478-482. http://dx.doi.org/10.1038/nature09001

[12] Ricciardi, M.J., Wu, E., Davidson, C.J., et al. (2001) Visualization of Discrete Microinfarction after Percutaneous Coronary Intervention Associated with Mild Creatine Kinase-MB Elevation. Circulation, 103, 2780-2783. http://dx.doi.org/10.1161/hc2301.092121

[13] Selvanayagam, J.B., Porto, I., Channon, K., et al. (2005) Troponin Elevation after Percutaneous Coronary Intervention Directly Represents the Extent of Irreversible Myocardial Injury: Insights from Cardiovascular Magnetic Resonance Imaging. Circulation, 111, 1027-1032. http://dx.doi.org/10.1161/01.CIR.0000156328.28485.AD

[14] Ioannidis, J.P., Karvouni, E. and Katritsis, D.G. (2003) Mortality Risk Conferred by Small Elevations of Creatine Kinase-MB Isoenzyme after Percutaneous Coronary Intervention. Journal of the American College of Cardiology, 42, 1406-1411. http://dx.doi.org/10.1016/S0735-1097(03)01044-1

[15] Do, L., Wilson, M.W., Krug, R., Hetts, S.W. and Saeed, M. (2015) MRI Monitoring of Function, Perfusion and Viability in Microembolized Moderately Ischemic Myocardium. International Journal of Cardiovascular Imaging, 31, 11791190. http://dx.doi.org/10.1007/s10554-015-0673-3 
[16] Böse, D., von Birgelen, C., Zhou, X.Y., Schmermund, A., Philipp, S., Sack, S., Konorza, T., Mohlenkamp, S., Leineweber, K., Kleinbongard, P., Wijns, W., Heusch, G. and Erbel, R. (2008) Impact of Atherosclerotic Plaque Composition on Coronary Microembolization during Percutaneous Coronary Interventions. Basic Research in Cardiology, 103, 587-597. http://dx.doi.org/10.1007/s00395-008-0745-9

[17] Hong, Y.J., Mintz, G.S., Kim, S.W., et al. (2009) Impact of Plaque Composition on Cardiac Troponin Elevation after Percutaneous Coronary Intervention: An Ultrasound Analysis. Journal of the American College of Cardiology: Cardiovascular Imaging, 2, 458-468. http://dx.doi.org/10.1016/j.jcmg.2008.12.020

[18] Uetani, T., Amano, T., Ando, H., et al. (2008) The Correlation between Lipid Volume in the Target Lesion, Measured by Integrated Backscatter Intravascular Ultrasound, and Post-Procedural Myocardial Infarction in Patients with Elective Stent Implantation. European Heart Journal, 29, 1714-1720. http://dx.doi.org/10.1093/eurheartj/ehn248

[19] Lang, R.M., Bierig, M., Devereux, R.B., et al. (2005) Recommendations for Chamber Quantification: A Report from the American Society of Echocardiography's Guidelines and Standards Committee and the Chamber Quantification Writing Group, Developed in Conjunction with the European Association of Echocardiography, a Branch of the European Society of Cardiology. Journal of the American Society of Echocardiography, 18, 1440-1463. http://dx.doi.org/10.1016/j.echo.2005.10.005

[20] Møller, J.E., Hillis, G.S., Oh, J.K., et al. (2006) Wall Motion Score Index and Ejection Fraction for Risk Stratification after Acute Myocardial Infarction. American Heart Journal, 151, 419-425. http://dx.doi.org/10.1016/j.ahj.2005.03.042

[21] Reisner, S.A., Lysyansky, P., Agmon, Y., Mutlak, D., Lessick, J. and Friedman, Z. (2004) Global Longitudinal Strain: A Novel Index of Left Ventricular Systolic Function. Journal of the American Society of Echocardiography, 17, 630 633. http://dx.doi.org/10.1016/j.echo.2004.02.011

[22] Bodi, V., Monmeneu, J.V., Ortiz-Perez, J.T., et al. (2016) Prediction of Reverse Remodeling at Cardiac MR Imaging Soon after First ST-Segment-Elevation Myocardial Infarction: Results of a Large Prospective Registry. Radiology, 278, 54-63. http://dx.doi.org/10.1148/radiol.2015142674

[23] Porto, I., Selvanayagam, J.B., Van Gaal, W.J., et al. (2006) Plaque Volume and Occurrence and Location of Periprocedural Myocardial Necrosis after Percutaneous Coronary Intervention: Insights from Delayed-Enhancement Magnetic Resonance Imaging, Thrombolysis in Myocardial Infarction Myocardial Perfusion Grade Analysis, and Intravascular ultrasound. Circulation, 114, 662-669. http://dx.doi.org/10.1161/CIRCULATIONAHA.105.593210

[24] Bahrmann, P., Werner, G.S., Heusch, G., et al. (2007) Detection of Coronary Microembolization by Doppler Ultrasound in Patients with Stable Angina Pectoris Undergoing Elective Percutaneous Coronary Interventions. Circulation, 115, 600-608. http://dx.doi.org/10.1161/CIRCULATIONAHA.106.660779

[25] Porto, I., Biasucci, L.M., De Maria, G.L., et al. (2012) Intracoronary Microparticles and Microvascular Obstruction in Patients with ST Elevation Myocardial Infarction Undergoing Primary Percutaneous Intervention. European Heart Journal, 33, 2928-2938. http://dx.doi.org/10.1093/eurheartj/ehs065

[26] Topol, E.J. and Yadav, J.S. (2000) Recognition of the Importance of Embolization in Atherosclerotic Vascular Disease. Circulation, 101, 570-580. http://dx.doi.org/10.1161/01.CIR.101.5.570

[27] Skyschally, A., Haude, M., Dorge, H., et al. (2004) Glucocorticoid Treatment Prevents Progressive Myocardial Dysfunction Resulting from Experimental Coronary Microembolization. Circulation, 109, 2337-2342. http://dx.doi.org/10.1161/01.CIR.0000127961.66744.F4

[28] Skyschally, A., Gres, P., Hoffmann, S., et al. (2007) Bidirectional Role of Tumor Necrosis Factor-Alpha in Coronary Microembolization: Progressive Contractile Dysfunction versus Delayed Protection against Infarction. Circulation Research, 100, 140-146. http://dx.doi.org/10.1161/01.RES.0000255031.15793.86

[29] Bajwa, H.Z., Do, L., Suhail, M., et al. (2014) MRI Demonstrates a Decrease in Myocardial Infarct Healing and Increase in Compensatory Ventricular Hypertrophy Following Mechanical Microvascular Obstruction. Journal of Magnetic Resonance Imaging, 40, 906-914. http://dx.doi.org/10.1002/jmri.24431

[30] Heusch, P., Nensa, F. and Heusch, G. (2015) Is MRI Really the Gold Standard for the Quantification of Salvage from Myocardial Infarction? Circulation Research, 117, 222-224. http://dx.doi.org/10.1161/CIRCRESAHA.117.306929

[31] Kwong, R.Y., Chan, A.K., Brown, K.A., et al. (2006) Impact of Unrecognized Myocardial Scar Detected by Cardiac Magnetic Resonance Imaging on Event-Free Survival in Patients Presenting with Signs or Symptoms of Coronary Artery Disease. Circulation, 113, 2733-2743. http://dx.doi.org/10.1161/CIRCULATIONAHA.105.570648

[32] Simonetti, O., Kim, R., Fieno, D., et al. (2001) An Improved MR Imaging Technique for the Visualization of Myocardial Infarction. Radiology, 218, 215-223. http://dx.doi.org/10.1148/radiology.218.1.r01ja50215

[33] Saeed, M., Hetts, S.W., Do, L. and Wilson, M.W. (2013) MRI Study on Volume Effects of Coronary Emboli on Myocardial Function, Perfusion and Viability. International Journal of Cardiology, 165, 93-99. http://dx.doi.org/10.1016/j.ijcard.2011.07.096 
[34] Saeed, M., Hetts, S.W., Do, L. and Wilson, M.W. (2013) Coronary Microemboli Effects in Preexisting Acute Infarcts in a Swine Model: Cardiac MR Imaging Indices, Injury Biomarkers, and Histopathologic Assessment. Radiology, 268, 98-108. http://dx.doi.org/10.1148/radiol.13122286

[35] Dewey, M., Laule, M., Taupitz, M., et al. (2006) Myocardial Viability: Assessment with Three-Dimensional MR Imaging in Pigs and Patients. Radiology, 239, 703-709. http://dx.doi.org/10.1148/radiol.2393050586

[36] Bauner, K.U., Muehling, O., Theisen, D., et al. (2009) Assessment of Myocardial Viability with 3D MRI at 3 T. American Journal of Roentgenology, 192, 1645-1650. http://dx.doi.org/10.2214/AJR.08.1394

[37] Goetti, R., Kozerke, S., Donati, O.F., et al. (2011) Acute, Subacute, and Chronic Myocardial Infarction: Quantitative Comparison of 2D and 3D Late Gadolinium Enhancement MR Imaging. Radiology, 259, 704-711. http://dx.doi.org/10.1148/radiol.11102216

[38] Yan, A.T., Shayne, A.J., Brown, K.A., et al. (2006) Characterization of the Peri-Infarct Zone by Contrast-Enhanced Cardiac Magnetic Resonance Imaging Is a Powerful Predictor of Post-Myocardial Infarction Mortality. Circulation, 114, 32-39. http://dx.doi.org/10.1161/CIRCULATIONAHA.106.613414

[39] O’Regan, D.P., Ahmed, R., Neuwirth, C., et al. (2009) Cardiac MRI of Myocardial Salvage at the Peri-Infarct Border Zones after Primary Coronary Intervention. American Journal of Physiology_Heart and Circulatory Physiology, 297, H340-H346. http://dx.doi.org/10.1152/ajpheart.00011.2009

[40] Crawford, T., Cowger, J., Desjardins, B., et al. (2010) Determinants of Postinfarction Ventricular Tachycardia. Circulation: Arrhythmia and Electrophysiology, 3, 624-631. http://dx.doi.org/10.1161/circep.110.945295

[41] Carlsson, M., Saloner, D., Martin, A.J., Ursell, P.C. and Saeed, M. (2010) Heterogeneous Microinfarcts Caused by Coronary Microemboli: Evaluation with Multidetector CT and MR Imaging in a Swine Model. Radiology, 254, 718728. http://dx.doi.org/10.1148/radiol.09090527

[42] Angeli, F.S., Shapiro, M., Amabile, N., et al. (2009) Left Ventricular Remodeling after Myocardial Infarction: Characterization of a Swine Model on Beta-Blocker Therapy. Comparative Medicine, 59, 272-279.

[43] Breuckmann, F., Nassenstein, K., Bucher, C., et al. (2009) Systematic Analysis of Functional and Structural Changes after Coronary Microembolization: A Cardiac Magnetic Resonance Imaging Study. Journal of the American College of Cardiology: Cardiovascular Imaging, 2, 121-130. http://dx.doi.org/10.1016/j.jcmg.2008.10.011

[44] Nassenstein, K., Breuckmann, F., Bucher, C., et al. (2008) How Much Myocardial Damage Is Necessary to Enable Detection of Focal Late Gadolinium Enhancement at Cardiac MR Imaging? Radiology, 249, 829-835. http://dx.doi.org/10.1148/radiol.2493080457

[45] Choi, J.W., Gibson, C.M., Murphy, S.A., et al. (2004) Myonecrosis Following Stent Placement: Association between Impaired TIMI Myocardial Perfusion Grade and MRI Visualization of Microinfarction. Catheterization and Cardiovascular Interventions, 61, 472-476. http://dx.doi.org/10.1002/ccd.20024

[46] Fernández-Jiménez, R., Fuster, V. and Ibáñez, B. (2015) Reply: Myocardial Edema Should Be Stratified According to the State of Cardiomyocytes within the Ischemic Region. Journal of the American College of Cardiology, 65, 23562357. http://dx.doi.org/10.1016/j.jacc.2015.02.070

[47] Kim, H.W., Van Assche, L., Jennings, R.B., et al. (2015) Relationship of T2-Weighted MRI Myocardial Hyperintensity and the Ischemic Area-At-Risk. Circulation Research, 117, 254-265. http://dx.doi.org/10.1161/CIRCRESAHA.117.305771

[48] Arheden, H., Saeed, M., Higgins, C.B., et al. (2000) Reperfused Rat Myocardium Subjected to Various Durations of Ischemia: Estimation of the Distribution Volume of Contrast Material with Echo-Planar MR Imaging. Radiology, 215, 520-528. http://dx.doi.org/10.1148/radiology.215.2.r00ma38520

[49] Piechnik, S., Ferreira, V., Lewandowski, A., et al. (2013) Normal Variation of Magnetic Resonance T1 Relaxation Times in the Human Population at 1.5 T Using ShMOLLI. Journal of Cardiovascular Magnetic Resonance, 15, 13. http://dx.doi.org/10.1186/1532-429X-15-13

[50] Fontana, M., Banypersad, S.M., Treibel, T.A., et al. (2014) Native T1 Mapping in Transthyretin Amyloidosis. Journal of the American College of Cardiology: Cardiovascular Imaging, 7, 157-165. http://dx.doi.org/10.1016/j.jcmg.2013.10.008

[51] Puntmann, V.O., Voigt, T., Chen, Z., et al. (2013) Native T1 Mapping in Differentiation of Normal Myocardium from Diffuse Disease in Hypertrophic and Dilated Cardiomyopathy. Journal of the American College of Cardiology: Cardiovascular Imaging, 6, 475-484. http://dx.doi.org/10.1016/j.jcmg.2012.08.019

[52] Liu, C.-Y., Bluemke, D.A., Gerstenblith, G., et al. (2014) Reference Values of Myocardial Structure, Function, and Tissue Composition by Cardiac Magnetic Resonance in Healthy African-Americans at 3T and Their Relations to Serologic and Cardiovascular Risk Factors. The American Journal of Cardiology, 114, 789-795. http://dx.doi.org/10.1016/j.amjcard.2014.06.007

[53] Bull, S., White, S.K., Piechnik, S.K., et al. (2013) Human Non-Contrast T1 Values and Correlation with Histology in 
Diffuse Fibrosis. Heart, 99, 932-937. http://dx.doi.org/10.1136/heartjnl-2012-303052

[54] Karamitsos, T.D., Piechnik, S.K., Banypersad, S.M., et al. (2013) Noncontrast T1 Mapping for the Diagnosis of Cardiac Amyloidosis. Journal of the American College of Cardiology: Cardiovascular Imaging, 6, 488-497. http://dx.doi.org/10.1016/j.jcmg.2012.11.013

[55] Dall’Armellina, E., Piechnik, S., Ferreira, V., et al. (2012) Cardiovascular Magnetic Resonance by Non-Contrast T1Mapping Allows Assessment of Severity of Injury in Acute Myocardial Infarction. Journal of Cardiovascular Magnetic Resonance, 14, 15. http://dx.doi.org/10.1186/1532-429X-14-15

[56] Messroghli, D.R., Walters, K., Plein, S., et al. (2007) Myocardial $T_{1}$ Mapping: Application to Patients with Acute and Chronic Myocardial Infarction. Journal of Cardiovascular Magnetic Resonance, 58, 34-40. http://dx.doi.org/10.1002/mrm.21272

[57] Giri, S., Chung, Y.-C., Merchant, A., et al. (2009) T2 Quantification for Improved Detection of Myocardial Edema. Journal of Cardiovascular Magnetic Resonance, 11, 56. http://dx.doi.org/10.1186/1532-429X-11-56

[58] Saeed, M., Hetts, S.W., English, J., Do, L. and Wilson, M.W. (2011) Quantitative and Qualitative Characterization of the Acute Changes in Myocardial Structure and Function after Distal Coronary Microembolization Using MDCT. Academic Radiology, 18, 479-487. http://dx.doi.org/10.1016/j.acra.2010.11.016

[59] Jablonowski, R., Wilson, M.W., Joudi, N., Hetts, S.W. and Saeed, M. (2014) Three-Dimensional MRI Assessments of Patchy and Large Myocardial Infarction in Beating and Nonbeating Swine Hearts: Validation with Microscopy. Academic Radiology, 21, 1048-1055. http://dx.doi.org/10.1016/j.acra.2014.03.012

[60] Jablonowski, R., Wilson, M.W., Do, L., Hetts, S.W. and Saeed, M. (2015) Multidetector CT Measurement of Myocardial Extracellular Volume in Acute Patchy and Contiguous Infarction: Validation with Microscopic Measurement. $R a-$ diology, 274, 370-378. http://dx.doi.org/10.1148/radiol.14140131

[61] Malyar, N.M., Gossl, M., Beighley, P.E., and Ritman, E.L. (2004) Relationship between Arterial Diameter and Perfused Tissue Volume in Myocardial Microcirculation: A Micro-CT-Based Analysis. American Journal of Physiology-Heart and Circulatory Physiology, 286, H2386-H2392. http://dx.doi.org/10.1152/ajpheart.00682.2003

[62] Carlsson, M., Martin, A.J., Ursell, P.C., Saloner, D. and Saeed, M. (2009) Magnetic Resonance Imaging Quantification of Left Ventricular Dysfunction Following Coronary Microembolization. Magnetic Resonance in Medicine, 61, 595602. http://dx.doi.org/10.1002/mrm.21869

[63] Carlsson, M., Wilson, M., Martin, A.J. and Saeed, M. (2009) Myocardial Microinfarction after Coronary Microembolization in Swine: MR Imaging Characterization. Radiology, 250, 703-713. http://dx.doi.org/10.1148/radiol.2503081000

[64] Suhail, M.S., Wilson, M.W., Hetts, S.W. and Saeed, M. (2013) Magnetic Resonance Imaging Characterization of Circumferential and Longitudinal Strain under Various Coronary Interventions in Swine. World Journal of Radiology, 5, 472-483. http://dx.doi.org/10.4329/wjr.v5.i12.472

[65] Monreal, G., Gerhardt, M.A., Kambara, A., Abrishamchian, A.R., Bauer, J.A. and Goldstein, A.H. (2004) Selective Microembolization of the Circumflex Coronary Artery in an Ovine Model: Dilated, Ischemic Cardiomyopathy and Left Ventricular Dysfunction. Journal of Cardiac Failure, 10, 174-183. http://dx.doi.org/10.1016/j.cardfail.2003.08.013

[66] Ma, J., Qian, J., Ge, J., et al. (2012) Changes in Left Ventricular Ejection Fraction and Coronary Flow Reserve after Coronary Microembolization. Archives of Medical Science, 8, 63-69. http://dx.doi.org/10.5114/aoms.2012.27283

[67] Ma, J., Qian, J., Chang, S., et al. (2014) Left Ventricular Remodeling with Preserved Function after Coronary Microembolization: The Effect of Methylprednisolone. European Journal of Medical Research, 19, 7. http://dx.doi.org/10.1186/2047-783X-19-7

[68] Cimino, S., Canali, E., Petronilli, V., et al. (2013) Global and Regional Longitudinal Strain Assessed by Two-Dimensional Speckle Tracking Echocardiography Identifies Early Myocardial Dysfunction and Transmural Extent of Myocardial Scar in Patients with Acute ST Elevation Myocardial Infarction and Relatively Preserved LV Function. European Heart Journal—Cardiovascular Imaging, 14, 805-811. http://dx.doi.org/10.1093/ehjci/jes295

[69] Galiuto, L. (2004) Optimal Therapeutic Strategies in the Setting of Post-Infarct No Reflow: The Need for a Pathogenetic Classification. Heart, 90, 123-125. http://dx.doi.org/10.1136/hrt.2003.020800

[70] Jain, A., Mahmarian, J.J., Borges-Neto, S., et al. (1988) Clinical Significance of Perfusion Defects by Thallium-201 Single Photon Emission Tomography Following Oral Dipyridamole Early after Coronary Angioplasty. Journal of the American College of Cardiology, 11, 970-976. http://dx.doi.org/10.1016/S0735-1097(98)90053-5

[71] Hardoff, R., Shefer, A., Gips, S., et al. (1990) Predicting Late Restenosis after Coronary Angioplasty by Very Early (12 to 24 h) Thallium-201 Scintigraphy: Implications with Regard to Mechanisms of Late Coronary Restenosis. Journal of the American College of Cardiology, 15, 1486-1492. http://dx.doi.org/10.1016/0735-1097(90)92815-J

[72] Skyschally, A., Leineweber, K., Gres, P., Haude, M., Erbel, R. and Heusch, G. (2006) Coronary Microembolization. Basic Research in Cardiology, 101, 373-382. http://dx.doi.org/10.1007/s00395-006-0616-1 
[73] Skyschally, A., Schulz, R., Erbel, R. and Heusch, G. (2002) Reduced Coronary and Inotropic Reserves with Coronary Microembolization. American Journal of Physiology—Heart and Circulatory Physiology, 282, H611-H614.

[74] Jin, H., Yun, H., Ma, J., et al. (2016) Coronary Microembolization with Normal Epicardial Coronary Arteries and No Visible Infarcts on Nitrobluetetrazolium Chloride-Stained Specimens: Evaluation with Cardiac Magnetic Resonance Imaging in a Swine Model. Korean Journal of Radiology, 17, 83-92.

[75] Selvanayagam, J.B., Cheng, A.S., Jerosch-Herold, M., et al. (2007) Effect of Distal Embolization on Myocardial Perfusion Reserve after Percutaneous Coronary Intervention: A Quantitative Magnetic Resonance Perfusion Study. Circulation, 116, 1458-1464. http://dx.doi.org/10.1161/CIRCULATIONAHA.106.671909

[76] Mohlenkamp, S., Beighley, P.E., Pfeifer, E.A., et al. (2003) Intramyocardial Blood Volume, Perfusion and Transit Time in Response to Embolization of Different Sized Microvessels. Cardiovascular Research, 57, 843-852. http://dx.doi.org/10.1016/S0008-6363(02)00736-8

[77] Bai, Y., Hu, L., Yu, D., et al. (2015) Evolution of Coronary Flow in an Experimental Slow Flow Model in Swines: Angiographic and Pathological Insights. BioMed Research International, 2015, Article ID: 623986. http://dx.doi.org/10.1155/2015/623986

[78] Weihrauch, D., Zimmermann, R., Arras, M. and Schaper, J. (1994) Expression of Extracellular Matrix Proteins and the Role of Fibroblasts and Macrophages in Repair Processes in Ischemic Porcine Myocardium. Cellular \& Molecular Biology Research, 40, 105-116.

[79] Nahrendorf, M., Swirski, F.K., Aikawa, E., et al. (2007) The Healing Myocardium Sequentially Mobilizes Two Monocyte Subsets with Divergent and Complementary Functions. The Journal of Experimental Medicine, 204, 3037-3047. http://dx.doi.org/10.1084/jem.20070885

[80] Frangogiannis, N.G. (2006) The Mechanistic Basis of Infarct Healing. Antioxidants \& Redox Signaling, 8, $1907-1939$. http://dx.doi.org/10.1089/ars.2006.8.1907

[81] Nahrendorf, M., Pittet, M.J. and Swirski, F.K. (2010) Monocytes: Protagonists of Infarct Inflammation and Repair after Myocardial Infarction. Circulation, 121, 2437-2445. http://dx.doi.org/10.1161/CIRCULATIONAHA.109.916346

[82] Alam, S.R., Shah, A.S.V., Richards, J., et al. (2012) Ultrasmall Superparamagnetic Particles of Iron Oxide in Patients with Acute Myocardial Infarction: Early Clinical Experience. Circulation: Cardiovascular Imaging, 5, 559-565. http://dx.doi.org/10.1161/circimaging.112.974907

[83] Saeed, M., Bajwa, H.Z., Do, L., Hetts, S.W. and Wilson, M.W. (2016) Multi-Detector CT and MRI of Microembolized Myocardial Infarct: Monitoring of Left Ventricular Function, Perfusion, and Myocardial Viability in a Swine Model. Acta Radiologica, 57, 215-224. http://dx.doi.org/10.1177/0284185115574737

[84] Ertl, G. and Frantz, S. (2005) Healing after Myocardial Infarction. Cardiovascular Research, 66, $22-32$. http://dx.doi.org/10.1016/j.cardiores.2005.01.011

[85] Kloner, R.A. (2011) No-Reflow Phenomenon: Maintaining Vascular Integrity. Journal of Cardiovascular Pharmacology and Therapeutics, 16, 244-250. http://dx.doi.org/10.1177/1074248411405990

[86] Wu, K.C. (2012) CMR of Microvascular Obstruction and Hemorrhage in Myocardial Infarction. Journal of Cardiovascular Magnetic Resonance, 14, 68. http://dx.doi.org/10.1186/1532-429X-14-68

[87] Lund, G.K., Stork, A., Muellerleile, K., et al. (2007) Prediction of Left Ventricular Remodeling and Analysis of Infarct Resorption in Patients with Reperfused Myocardial Infarcts by Using Contrast-Enhanced MR Imaging. Radiology, 245, 95-102. http://dx.doi.org/10.1148/radiol.2451061219

[88] Saeed, M., Lee, R.J., Weber, O., et al. (2006) Scarred Myocardium Imposes Additional Burden on Remote Viable Myocardium Despite a Reduction in the Extent of Area with Late Contrast MR Enhancement. European Radiology, 16, 827-836. http://dx.doi.org/10.1007/s00330-005-0052-x

[89] Choi, C.J., Haji-Momenian, S., Dimaria, J.M., et al. (2004) Infarct Involution and Improved Function during Healing of Acute Myocardial Infarction: The Role of Microvascular Obstruction. Journal of Cardiovascular Magnetic Resonance, 6, 917-925.

[90] Ingkanisorn, W.P., Rhoads, K.L., Aletras, A.H., Kellman, P. and Arai, A.E. (2004) Gadolinium Delayed Enhancement Cardiovascular Magnetic Resonance Correlates with Clinical Measures of Myocardial Infarction. Journal of the American College of Cardiology, 43, 2253-2259. http://dx.doi.org/10.1016/j.jacc.2004.02.046

[91] Hori, M., Gotoh, K., Kitakaze, M., et al. (1991) Role of Oxygen-Derived Free Radicals in Myocardial Edema and Ischemia in Coronary Microvascular Embolization. Circulation, 84, 828-840. http://dx.doi.org/10.1161/01.CIR.84.2.828

[92] Bolli, R. (1988) Oxygen-Derived Free Radicals and Postischemic Myocardial Dysfunction ("Stunned Myocardium”). Journal of the American College of Cardiology, 12, 239-249. http://dx.doi.org/10.1016/0735-1097(88)90381-6

[93] Chen, Z.-W., Qian, J.-Y., Ma, J.-Y., et al. (2014) TNF- $\alpha$-Induced Cardiomyocyte Apoptosis Contributes to Cardiac 
Dysfunction after Coronary Microembolization in Mini-Pigs. Journal of Cellular and Molecular Medicine, 18, 19531963. http://dx.doi.org/10.1111/jcmm.12342

[94] Arras, M., Strasser, R., Mohri, M., et al. (1998) Tumor Necrosis Factor-Alpha Is Expressed by Monocytes/Macrophages Following Cardiac Microembolization and Is Antagonized by Cyclosporine. Basic Research in Cardiology, 93, 97-107. http://dx.doi.org/10.1007/s003950050069

[95] Chen, Z., Qian, J., Ma, J., et al. (2013) Glucocorticoid Ameliorates Early Cardiac Dysfunction after Coronary Microembolization and Suppresses TGF- $\beta 1 /$ Smad3 and CTGF Expression. International Journal of Cardiology, 167, 22782284. http://dx.doi.org/10.1016/j.ijcard.2012.06.002

[96] Jin, H., Yun, H., Ma, J.-Y., et al. (2016) Assessment of the Acute Effects of Glucocorticoid Treatment on Coronary Microembolization Using Cine, First-Pass Perfusion, and Delayed Enhancement MRI. Journal of Magnetic Resonance Imaging, 43, 921-928.

[97] Cai, Z. and Semenza, G.L. (2005) PTEN Activity Is Modulated during Ischemia and Reperfusion: Involvement in the Induction and Decay of Preconditioning. Circulation Research, 97, 1351-1359. http://dx.doi.org/10.1161/01.RES.0000195656.52760.30

[98] Nguyen, M.M., Carlini, A.S., Chien, M.-P., et al. (2015) Stimuli-Responsive Materials: Enzyme-Responsive Nanoparticles for Targeted Accumulation and Prolonged Retention in Heart Tissue after Myocardial Infarction. Advanced Materials, 27, 5446-5446. http://dx.doi.org/10.1002/adma.201570243

\section{Submit or recommend next manuscript to SCIRP and we will provide best service for you:}

Accepting pre-submission inquiries through Email, Facebook, Linkedin, Twitter, etc A wide selection of journals (inclusive of 9 subjects, more than 200 journals)

Providing a 24-hour high-quality service

User-friendly online submission system

Fair and swift peer-review system

Efficient typesetting and proofreading procedure

Display of the result of downloads and visits, as well as the number of cited articles

Maximum dissemination of your research work

Submit your manuscript at: http://papersubmission.scirp.org/ 